Running Head: Subconscious Goal Pursuit

The Dynamic Effects of Subconscious Goal Pursuit on Resource Allocation, Task Performance, and Goal Abandonment

\title{
Citation:
}

Sitzmann, T., \& Bell, B. (2017). The dynamic effects of subconscious goal pursuit on resource allocation, task performance, and goal abandonment. Organizational Behavior and Human Decision Processes, 138, 1-14. 


\begin{abstract}
We test two potential boundary conditions for the effects of subconscious goals - the nature of the goal that is activated (achievement vs. underachievement) and conscious goal striving. Subconscious achievement goals increase the amount of time devoted to skill acquisition, and this increase in resource allocation leads to higher performance when conscious goals are neutral. However, specific conscious goals undermine the performance benefits of subconscious achievement goals. Subconscious underachievement goals cause individuals to abandon goal pursuit and this effect is mediated by task performance. Difficult conscious goals neutralize the detrimental effects of subconscious underachievement goals but only if implemented before performance is undermined. Overall, these results suggest that subconscious achievement goals facilitate task performance, subconscious underachievement goals trigger goal abandonment, and difficult conscious goals moderate these effects depending on the level of resource allocation and timing of goal implementation.
\end{abstract}

Keywords: Goal setting; subconscious goals; subconscious self-regulation; working memory capacity; resource allocation; goal abandonment 
Subconscious Goal Pursuit 3

\section{The Dynamic Effects of Subconscious Goal Pursuit on Resource Allocation, Task Performance, and Goal Abandonment}

Over a thousand studies have demonstrated the benefits of goal setting (Locke \& Latham, 1990, 2002). Goals are instrumental for directing attention, energizing effort, and increasing persistence, ultimately leading to higher performance. Yet, this stream of research and practical application has focused almost exclusively on consciously held goals, which are goals that can be verbalized and exert their effects via the intentional regulation of behavior. An emerging body of research, however, suggests that subconscious goals are as influential as conscious goals and may prove superior for guiding behavior when information processing resources are scarce (Bargh, Gollwitzer, Lee-Chai, Barndollar, \& Trötschel, 2001; Chartrand \& Bargh, 2002; Latham, Stajkovic, \& Locke, 2010).

Research that has examined subconscious goals to date has been primarily inductive (Stajkovic, Locke, \& Blair, 2006). As noted by Latham and colleagues (2010), these studies have demonstrated the effectiveness of subconscious goals but there is not a fully developed theory to explain the effects. An important step in theory building involves identifying boundary conditions for a phenomenon (Locke, 2007). Although recent work has begun to examine the boundary conditions for subconscious thought (Payne, Samper, Bettman, \& Francis-Luce, 2008), we know relatively little about the conditions under which subconscious goals have limited, or even negative, effects on performance. Indeed, Dijksterhuis (2014, p. 72) recently argued that research in this area "should pay more attention to the systematic investigation of boundary conditions and to more precise theorizing."

The purpose of this study is to examine two potential boundary conditions for the effects of subconscious goals. First, subconscious goals research has typically used achievement- 
oriented words (e.g., compete, succeed) or images (e.g., a woman winning a race) to prime subconscious achievement goals, defined as the automatic arousal of mental representations related to striving, exerting effort, and prevailing (e.g., Shantz \& Latham, 2009; Stajkovic et al., 2006). Although consistent with the prevailing notion that subconscious goals are "generally functional, beneficial, positive processes" (Chartrand \& Bargh, 2002, p. 34), focusing exclusively on achievement ignores the fact that people are exposed to a variety of environmental stimuli, some of which have the potential to prime maladaptive behavior. For example, priming can trigger indulgence (e.g., Zemack-Rugar, Bettman, \& Fitzsimons, 2007), disruptive social behaviors (e.g., rudeness, hostility, Bargh, Chen, \& Burrows, 1996), and other unhealthy behaviors (e.g., increased alcohol consumption, Carter, McNair, Corbin, \& Black, 1998). In the workplace, employees are regularly exposed to lazy and underperforming colleagues, online content related to failing, relaxing, and slacking from work, and other environmental stimuli that have the potential to activate subconscious underachievement goals. We define subconscious underachievement goals as the automatic arousal of mental representations related to laziness, sluggishness, and listlessness. Accordingly, we extend the subconscious goals literature by examining how individuals modify their behavior over time in response to changing environmental cues related to both achievement and underachievement.

Second, recent research has found that performance can be enhanced by combining subconscious achievement goals with conscious goals (Shantz \& Latham, 2009; Stajkovic et al., 2006). This finding has potentially important applied implications. For example, Stajkovic et al. (2006) suggested that it may be possible to increase sales performance by combining the routine practice of setting conscious sales goals with sales training that is seeded with appropriate prime words (e.g., sell, achieve, produce). Employees are often assigned difficult performance 
objectives (e.g., increase sales) while simultaneously being exposed to a variety of stimuli (e.g., other employees, online content) that can prime different types of subconscious goals. As Shantz and Latham (2009, p. 11) state, "The number of competing stimuli in a work setting, and the demands placed by management on employees for high productivity may vitiate the effect of a primed goal that is typically found under laboratory conditions." Moreover, studies that have examined the joint effects of subconscious and conscious goals have focused on tasks where individuals have already attained proficiency. In contrast, the current study examines the effects of subconscious and conscious goals for a task that requires individuals to devote substantial cognitive resources to knowledge and skill acquisition. Under such conditions, a difficult conscious goal may undermine, rather than enhance, the effects of a subconscious achievement goal by diverting cognitive resources from skill acquisition to goal regulation (Kanfer \& Ackerman, 1989; Winters \& Latham, 1996). At the same time, a challenging conscious goal may help to neutralize or inhibit the undermining effects of subconscious underachievement goals (e.g., Légal, Meyer, \& Delouvée, 2007; Shah, Friedman, \& Kruglanski, 2002). Hence, we examine conscious goal striving as a potential boundary condition for the effects of subconscious goals in cognitively demanding environments.

To examine these boundary conditions, we propose a process model of the effects of subconscious goals on three behavioral outcomes - resource allocation (i.e., the amount of time devoted to knowledge and skill acquisition), task performance (i.e., learning performance), and goal abandonment (i.e., attrition from training) — and examine how conscious goals moderate this process. Furthermore, we adopt a dynamic perspective that examines how this process unfolds over time and how individuals modify their behavior in response to changing conscious and subconscious goals. Adopting a dynamic perspective is invaluable due to mounting evidence that 
individuals repeatedly decide how to allocate time and resources throughout the workday and resource allocation decisions evolve in response to performance feedback and performance expectancies (Schmidt \& DeShon, 2007; Sitzmann \& Yeo, 2013). We add to this literature by examining whether task engagement also evolves in response to changing environmental stimuli. Finally, an experimenter has been present during task performance in prior studies of subconscious goals (see Latham \& Piccolo, 2012, for an exception), which has led to concerns about demand effects and experimenter bias (Latham et al., 2010). The current study was conducted entirely online, alleviating these concerns.

In the following section, we provide a theoretical overview of differences in the information processing requirements of subconscious and conscious goals. In addition, we address how subconscious goals are activated and their implications for behavior and implicit processes.

\section{Theoretical Overview of Subconscious and Conscious Goals}

Goal setting theory argues that specific difficult goals result in higher performance than neutral (i.e., “do your best”) or easy goals (Locke \& Latham, 1990, 2002). Goals affect performance through their influence on the direction, intensity, and persistence of effort and are most effective when individuals are committed to their goals and receive feedback on their performance (Locke \& Latham, 2002). Often goals focus on performance, or the level of task proficiency that one should strive to attain. However, under certain conditions — such as during complex tasks - it is advantageous to assign learning (rather than performance) goals, which focus on the acquisition of ideas or task strategies (e.g., Dishon-Berkovits, 2014; Masuda, Locke, \& Williams, 2015; Nahrgang et al., 2013; Tasa, Celani, \& Bell, 2013). Consistent with recent research examining the relationship between conscious and subconscious goals (e.g., Stajkovic et 
al., 2006), we focused on performance goals in the current research. This focus permits examining whether conscious performance goals shield against the potentially deleterious effects of subconscious underachievement goals. Furthermore, it is practically important to examine performance goals due to their widespread use within organizations (Ordóñez, Schweitzer, Galinksy, \& Bazerman, 2009). As Seijts and Latham (2005, p. 129) note, “Today's workforce continues to be under intense pressure to produce tangible results. They are in 'performance mode'."

The term subconscious suggests that individuals are unaware of both their goals and the fact that they have been affected by the environment (Latham et al., 2010). Subconscious goals operate automatically — without intention, guidance, and awareness — and are triggered by environmental cues (Aarts \& Dijksterhuis, 2003; Bargh, 1990; Chartrand \& Bargh, 2002), which is akin to background goals in goal systems theory (Kruglanski et al., 2002). The automatic nature of subconscious goals suggests that they do not require an act of conscious choice to be put into motion, and, once activated, subgoals, plans, and strategies for goal attainment are automatically pursued outside conscious awareness (Bargh et al., 2001; Gollwitzer \& Bargh, 1996). Subconscious goals stimulate implicit motivation - which is measured indirectly through projective techniques—whereas conscious goals stimulate explicit motivation-which is typically assessed with self-report measures (Latham et al., 2010). Implicit and explicit motivation have little or no overlap in variance and tap different facets of achievement motivation (Collins, Hanges, \& Locke, 2004; Schultheiss \& Brunstein, 2001; Spangler, 1992).

Subconscious goals are manipulated through priming, which refers to the temporary subconscious activation of a mental representation by cues in the environment (Bargh \& Chartrand, 2000; Shantz \& Latham, 2009). Two techniques are used to activate subconscious 
goals: subliminal and supraliminal priming (Latham et al., 2010; Stajkovic et al., 2006).

Subliminal priming involves presenting a stimulus rapidly so that it is not consciously perceived and then measuring how the stimulus affects behavior. Supraliminal priming involves exposing individuals to messages in the form of words or pictures, but in a manner where the relationship to the primary task is not readily obvious (Latham et al., 2010). For example, Latham and colleagues used an image of a person winning a race to activate subconscious achievement goals and found that priming achievement resulted in higher performance, relative to a no subconscious goal condition, and the vast majority of people were unaware that they had been primed (Latham \& Piccolo, 2012; Shantz, \& Latham, 2009, 2011).

The benefits of subconscious achievement goals may be particularly pronounced for tasks that place significant demands on attentional resources. Conscious goals can encumber attentional capacity during skill acquisition because they divert cognitive resources from task engagement toward goal regulation (Kanfer \& Ackerman, 1989; Latham et al., 2010). Ultimately, conscious performance goals can impair knowledge and skill acquisition because all cognitive resources are needed for task engagement (Kanfer \& Ackerman, 1989).

The limitations of attentional capacity necessitate extensive reliance on subconscious information processing (Shantz \& Latham, 2011). Subconscious achievement goal pursuit is adaptive because it operates effectively even when information processing resources are scarce, and it frees up space in conscious memory so that more of its capacity can be dedicated to task performance (Bargh et al., 2001; Chen \& Latham, 2014; Stajkovic et al., 2006). Shifting selfregulatory functions from conscious to subconscious control is an effective means of ensuring goal progress under challenging, complex, or unfamiliar circumstances when both goals focus on maximizing achievement (Bargh et al., 2001). Under these circumstances, individuals strive for 
achievement and all cognitive resources can be dedicated to task engagement. Although difficult performance goals are compatible with subconscious achievement goals, they may nonetheless undermine the benefits of priming achievement because conscious goals divert cognitive resources away from the task and toward goal regulation. Yet, we are unaware of any research that has examined how conscious and subconscious goals interact during tasks that tax information processing resources.

Subconscious underachievement goal pursuit may serve as an exception to the rule that conscious goal setting is uniformly disadvantageous when cognitive resources are taxed. Theoretically, subconscious underachievement goals undermine performance by stimulating implicit underachievement motivation. Although conscious goal setting necessitates that substantial resources are allocated toward goal regulation, difficult performance goals orient individuals toward achievement and, therefore, may mitigate the deleterious motivational effects of subconscious underachievement goals (Locke \& Latham, 1990). Thus, a difficult conscious goal may inhibit the activation of an alternative and incompatible subconsconscious underachievement goals (Köpetz, Faber, Fishbach, \& Kruglanski, 2011; Shah, Friedman, \& Kruglanski, 2002). This is akin to goal shielding, whereby difficult performance goals may protect against the potential distracting effects of subconscious underachievement goals (Shah et al., 2002). Specifically, the motivating power of difficult conscious goals may automatically inhibit alternative, incompatible goals, including the desire to be lazy and relax, which can be triggered by underachievement environmental stimuli. Ultimately, goal shielding enhances goal persistence and task performance (Shah et al., 2002).

Together this suggests that the highest performance should be attained when subconscious goals stimulate an implicit need for achievement and conscious goals are neutral. 
Under these circumstances, individuals strive for achievement and cognitive resources can be allocated to task engagement. In contrast, the lowest performance should be attained when subconscious goals stimulate an implicit need for underachievement and conscious goals are neutral. Neutral conscious goals will not arouse implicit or explicit motivation and should be ineffective at inhibiting the implicit underachievement motivation aroused by subconscious underachievement goals. Performance should fall between these two extremes when subconscious achievement or underachievement goals are paired with difficult conscious goals.

Moreover, the essence of achievement and underachievement environmental cues suggests that these messages should affect different aspects of goal striving behavior. The underlying message for achievement is success and exerting the effort necessary to attain success. Behaving in a manner consistent with this message should result in allocating additional resources toward task engagement, ultimately enhancing task performance. The underlying message for underachievement is laziness and slacking. The ultimate form of underachievement after one has started a task involves giving up on goal pursuit. Thus, we propose a process model by which subconscious achievement goals improve task performance via resource allocation and subconscious underachievement goals increase the probability of goal abandonment via task performance. Conscious goals are hypothesized to moderate these effects by determining the effectiveness of resource allocation and bringing the effectiveness of one's actions into conscious awareness.

Finally, we utilized a within-person design to repeatedly manipulate subconscious and conscious goals. This design feature is imperative for examining whether changes in goals lead to changes in behavior, which is aligned with the fact that environmental stimuli that trigger subconscious goals vary over time and individuals strive to attain different conscious goals 
throughout the workday. For example, a researcher may receive positive feedback from a coauthor on one manuscript in the morning — triggering achievement motivation-only to have that motivation undermined by a journal rejection letter later in the day. This process is further complicated by the fact that the individual may be striving to attain the difficult conscious goal of revising a manuscript for a top-tier journal by the end of the workday. Examining the dynamic interplay of conscious goals in the presence of subconscious achievement and underachievement goals is critical for understanding the host of factors that affect employees' motivation throughout the workday. We propose that these environmental stimuli along with conscious goal striving will result in fluctuations in achievement and underachievement motivation, ultimately affecting resource allocation, task performance, and goal abandonment. A within-person design also eliminates alternative explanations for observed effects because employees serve as their own control and individual differences that have compelling effects on resource allocation, task performance, and goal abandonment (e.g., cognitive ability and prior knowledge) are stable over time. Thus, changes in behavior from one assessment to the next can only be attributed to conscious and subconscious goals rather than individual differences.

In the following sections, we draw from the self-regulation and priming literatures to articulate the joint effects of subconscious and conscious goals on goal striving behavior. We begin with a discussion regarding the process by which subconscious achievement goals enhance task performance and then discuss the process by which subconscious underachievement goals initiate goal abandonment. 


\section{Subconscious Achievement Goals and Task Performance}

Messages conveying action, striving, and prevailing should increase resource allocation, ultimately enhancing skill acquisition as long as individuals are not simultaneously striving to attain conscious goals. Conscious goal setting may undermine the benefits of achievement messages and devoting additional time to learning by diverting attentional resources away from the task. Thus, we propose that the moderating effect of conscious goals must be taken into account to understand the dynamic interplay between subconscious achievement goals, time on task, and task performance (see Figure 1).

Achievement primes consist of messages that emphasize the relationship between effort exertion and goal attainment (Shantz \& Latham, 2009, 2011). For example, Latham and Piccolo (2012) primed achievement by exposing employees in a call center to a photograph of a woman winning a race. Behaviorally mimicking achievement-related environmental messages should ensure that individuals allocate increased resources toward skill acquisition. Behavioral mimicry is an innate tendancy; at birth, infants can smile, stick out their tongue, and open their mouth when they observe demonstrations of these behaviors by other people (Cheng \& Chartrand, 2003; Metzoff \& Moore, 1997). Thus, when individuals are exposed to images of people exerting effort and attaining success, they subconsciously process the images as reinforcing that effort leads to goal attainment. Strengthening the effort/performance link increases implicit achievement motivation, which manifests as increased resources directed toward the task at hand.

Prior research has focused limited attention on the mechanisms that account for the effects of subconscious achievement goals. Stajkovic and colleagues (2006) proposed that subconscious goals influence goal-directed energy exertion and recommended that research 
directly assess effort over an extended period of time to test this prediction. Thus, we measured the amount of time that individuals devoted to skill acquisition for a task that took several hours to complete, which is a substantially longer period of task engagement than that employed in most subconscious goals studies. Time on task serves as an objective, behavioral indicator of resource allocation and is more appropriate than self-report measures of regulatory engagement, which assess consciously accessible processes (Latham et al., 2010; Lord \& Levy, 1994; Stajkovic et al., 2006). Mimicking the effort exertion depicted in achievement primes should increase individuals' time on task, relative to when their subconscious goals are not primed.

H1: Subconscious achievement goals have a positive within-person effect on time on task, relative to the no subconscious goal control condition.

We also propose that whether subconscious achievement goals and time on task enhance performance is contingent upon conscious goal setting, and the shape of the subconscious by conscious goals interaction is contingent upon whether individuals are knowledgeable about the task requirements or acquiring knowledge and skills. Kanfer and Ackerman's (1989) resource allocation theory reveals that conscious goal setting imposes constraints upon working memory capacity, such that individuals attempt to regulate goal attainment along with completing the performance task. As long as the cognitive demands imposed by the performance task and goal regulation do not exceed working memory capacity, setting a conscious performance goal enhances task performance. Thus, for familiar tasks, both conscious performance goals and subconscious achievement goals are advantageous. Consistent with this perspective, Stajkovic et al. (2006) found difficult conscious goals enhanced the effect of subconscious achievement goals during a brainstorming task.

The greatest demands on cognitive resources are imposed when tasks are unfamiliar and individuals are learning the task requirements (Kanfer \& Ackerman, 1989; Kanfer, Ackerman, 
Murtha, Dugdale, \& Nelson, 1994). Thus, learning requires that individuals devote all available attentional resources toward skill acquisition. Simultaneously striving to attain conscious performance goals while acquiring a skill can impair task performance because conscious performance goals lead to devoting one's limited attentional resources toward goal regulation when resources need to be directed toward skill acquisition (Kanfer \& Ackerman, 1989; Locke \& Latham, 1990, 2002; Winters \& Latham, 1996). As such, relegating goal striving to the subconscious (in the absence of difficult conscious goals) should be an effective strategy for maximizing knowledge and skill acquisition when subconscious goals arouse achievement motivation. Under these conditions, individuals are motivated to achieve and attentional resources can be devoted to skill acquisition. Thus, subconscious achievement goals should result in the highest performance on skill acquisition tasks when conscious goals ask individuals to do their best rather than striving to improve their performance. ${ }^{1}$

H2: Conscious goal setting moderates the within-person effect of subconscious achievement goals on task performance. Subconscious achievement goals have a more positive effect on task performance when conscious goals are neutral rather than difficult.

Hypothesis 1 proposes that subconscious achievement goals increase the amount of time devoted to learning, and this should translate into improved task performance when conscious performance goals are neutral. Time on task is one of the strongest predictors of performance during skill acquisition, such that devoting additional time enhances task performance (Sitzmann \& Ely, 2010, 2011; Sitzmann \& Johnson, 2012a, 2012b; Vancouver \& Kendall, 2006). However,

\footnotetext{
${ }^{1}$ Along with the difficult and neutral conscious goal conditions, we included an easy conscious goal condition. Neutral goals ask people to do their best, whereas easy goals represent a standard that is below the level that most people would attain without setting a goal. We do not hypothesize that easy goals will differ from neutral goals on the effects under investigation, but included both conditions to establish the boundaries of conscious goal setting. Further, the easy goal condition makes it possible to compare the current results to Stajkovic et al. (2006) and contributes to the broader goal of replicating research findings.
} 
conscious performance goals can undermine the time devoted to skill acquisition by redirecting resources from skill acquisition toward goal regulation when all available resources are needed for skill acquisition (Kanfer \& Ackerman, 1989; Locke \& Latham, 1990, 2002; Winters \& Latham, 1996). Regulating performance goals can detract from learning because individuals become "so anxious to succeed that they scramble to discover strategies in an unsystematic way and fail to learn what is effective" (Locke \& Latham, 2002, p. 707). Thus, time on task should exert a more positive effect on task performance when individuals are striving for neutral rather than difficult conscious performance goals.

H3: Conscious goal setting moderates the within-person effect of resource allocation on task performance. Time on task has a more positive effect on performance when conscious goals are neutral rather than difficult.

Together Hypotheses 1 through 3 represents a direct effect and second stage moderation model (see Figure 1; Edwards \& Lambert, 2007). The moderated direct effect focuses on the allocation of resources toward goal regulation versus skill acquisition while assuming a fixed pool of resources. Regulating conscious performance goals can impair task performance by consuming attentional resources that are needed for skill acquisition. Thus, relegating goal striving to the subconscious (in the absence of difficult conscious goals) should maximize skill acquisition when subconscious goals arouse achievement motivation.

The second stage moderation model suggests that subconscious achievement goals increase the amount of time devoted to skill acquisition, and in the absence of conscious goal setting, the increase in resources enhances task performance. However, difficult conscious performance goals mitigate the extent to which the additional time devoted to learning translates into improved performance. Thus, time on task has a more positive effect on task performance when conscious goals are neutral rather than difficult. 


\section{Subconscious Underachievement Goals and Goal Abandonment}

Research on goal contagion and behavioral mimicry demonstrates that people often mirror the maladaptive behavior of others, regardless of whether the person is physically present or appears only in an image (Aarts, Gollwitzer, \& Hassin, 2004; Chartrand, Maddux, \& Lakin, 2005). Behaviorally mimicking underachievement should undermine task performance, ultimately causing individuals to abandon work-related goals. Moreover, conscious goals should moderate this process, such that difficult conscious goals may prove advantageous for combatting implicit underachievement motivation as long as they are implemented before subconscious underachievement goals undermine performance (see Figure 1).

Underachievement runs counter to the effortful engagement required for skill acquisition. Thus, environmental messages conveying underachievement may diminish motivation for goal pursuit, undermining the ambition necessary for prolonged goal striving, ultimately leading to abandoning work-related goals. Just as subconscious achievement goals are expected to arouse implicit motives related to effort and success, subconscious underachievement goals should stimulate implicit motives related to laziness and failure (Schultheiss \& Brunstein, 2010). For example, when individuals are exposed to messages conveying tiredness, laziness, or lethargysuch as a man yawning and rubbing his eyes or an employee asleep at her desk—behavioral mimicry suggests that these messages may induce underachievement, ultimately leading to goal abandonment.

H4: Subconscious underachievement goals have a positive within-person effect on goal abandonment, relative to the no subconscious goal control condition.

We also propose that task performance represents one mechanism through which subconscious underachievement goals impact goal abandonment. The motivation literature points out that individuals may either waste time (increasing unproductive time on task) or 
procrastinate (decreasing time on task) if they are not motivated to pursue a goal (Steel, 2007;

Steel \& König, 2006). Given these distinct and contradictory behavioral responses, we did not hypothesize a main effect of subconscious underachievement goals on time on task. Instead, we focused on the effect of these goals on performance, which theory suggests should be negative regardless of whether underachievement motives manifest as wasting time or procrastination.

Our argument for the deleterious effect of subconscious underachievement goals on task performance is aligned with research that has demonstrated that subconscious achievement goals enhance task performance (Shantz \& Latham, 2009, 2011; Stajkovic et al., 2006). Messages conveying laziness and lethargy may undermine performance by causing individuals to be less productive with their time or to choose not to devote time to task engagement. Fundamentally, the demotivating power of implicit underachievement motivation should undermine performance, ultimately leading to goal abandonment. This is consistent with research demonstrating that performance is a proximal antecedent of goal abandonment (Sitzmann \& Ely, 2010; Sitzmann, Ely, Bell, \& Bauer, 2010; Sitzmann \& Johnson, 2012a).

H5: Task performance mediates the within-person effect of subconscious underachievement goals on goal abandonment. Subconscious underachievement goals have a negative effect on task performance, relative to the no subconscious goal control condition, and task performance has a negative effect on goal abandonment.

Finally, we argue that conscious goals moderate both the subconscious underachievement goals to performance and performance to goal abandonment relationships. Although difficult performance goals divert cognitive resources from task engagement toward goal striving, they may prove advantageous for counteracting the effect of implicit underachievement motivation on performance. Individuals must be motivated if they are going to attain high performance standards (Kanfer \& Ackerman, 1989; Locke \& Latham, 2002). Achievement motivation can be triggered with either conscious or subconscious goals, but subconscious underachievement goals 
undermine the achievement motivation needed to attain success. Difficult performance goals may counteract the underachievement motivation triggered by subconscious underachievement goals by activating explicit motivation and empowering individuals to strive toward high standards. Thus, a difficult conscious goal may have a shielding effect, inhibiting the activation of an alternative, incompatible subconscious underachievement goal (Köpetz, Faber, Fishbach, \& Kruglanski, 2011; Shah et al., 2002).

Prior research has only focused on subconscious achievement goals so the potential implications of these conflicting subconscious and conscious goals has not been examined. However, Shantz and Latham (2009) found that conscious $(d=.49)$ and subconscious $(d=.43)$ goals had comparable effects on performance, suggesting that setting a difficult performance goal may counteract or neutralize the negative effect of subconscious underachievement goals on performance.

H6: Conscious goal setting moderates the within-person effect of subconscious underachievement goals on task performance. Subconscious underachievement goals have a more negative effect on task performance when conscious goals are neutral rather than difficult.

Although difficult performance goals should be advantageous when implemented before performance is undermined, they may exacerbate the effect of poor performance on goal abandonment when implemented following an episode of poor performance. Individuals rely on their expectancies for goal attainment to decide whether to persist or disengage from goal pursuit (Bandura, 1991; Carver \& Scheier, 1998; Locke \& Latham, 1990). Expectancies are based on goal progress and goal difficulty, such that poor performance and difficult goals result in low expectancies for goal attainment, increasing the probability of goal abandonment (Schmidt \& Dolis, 2009). Poor performance suggests that individuals are not attaining difficult performance goals and may be wasting time trying to acquire a skill (Frese \& Zapf, 1994; Sitzmann et al., 
2010). Thus, the probability of goal abandonment is greater following low than high

performance (Sitzmann \& Ely, 2010; Sitzmann et al., 2010; Sitzmann \& Johnson, 2012a).

Setting a difficult performance goal should exacerbate this effect due to the magnitude of goalperformance discrepancy that must be overcome for goal attainment (Carver \& Scheier, 2000). Together, poor performance and difficult conscious goals should decrease individuals' expectancies, increasing the probability of goal abandonment (Schmidt \& Dolis, 2009).

H7: Conscious goal setting moderates the within-person effect of task performance on goal abandonment. The probability of goal abandonment is higher following low than high performance, and the strength of this effect is greater when conscious goals are difficult rather than neutral.

Together Hypotheses 4 through 7 represent a first and second stage moderation model (see Figure 1; Edwards \& Lambert, 2007). Foremost, subconscious underachievement goals have a direct effect on goal abandonment because they diminish motivation for goal pursuit. Second, the effect of subconscious underachievement goals on goal abandonment are mediated by task performance and both the subconscious underachievement goals to task performance and task performance to goal abandonment effects are moderated by conscious goal setting. Difficult (relative to neutral) conscious goals buffer the negative effect of subconscious underachievement goals on performance as long as they are implemented before performance is impaired by subconscious goals. However, if difficult conscious goals are implemented after performance is impaired, conscious goal setting strengthens the negative effect of task performance on goal abandonment.

\section{Method}

\section{Participants}

Six-hundred sixteen adults were recruited online and successfully enrolled in the experiment. The educational attainment of participants varied greatly: $2 \%$ had not completed 
high school, $41 \%$ had a high school diploma or general education degree, $25 \%$ had an associate or technical degree, $23 \%$ had a bachelor's degree, and $9 \%$ had a graduate degree. The majority of participants were employed full-time (31\%), whereas $18 \%$ were employed part-time, $38 \%$ were unemployed, $8 \%$ were retired, and $5 \%$ were students. On average, participants worked 22 hours a week $(S D=19)$. The average age was 50 years $(S D=12$; ages ranged from 18 to 86$)$ and $82 \%$ were female. $^{2}$

\section{Experimental Design and Procedure}

Advertisements for free online Microsoft Word training were posted on Google, and individuals who clicked on an advertisement were directed to the learning management system (LMS) that hosted the course. The LMS provided a broad overview of the topics covered in training and informed participants that training was being offered free of charge in exchange for research participation. Individuals who elected to enroll in the course electronically agreed to the informed consent and were granted access to training.

The training focused on Microsoft Word and consisted of 10 modules that progressed from basic to advanced functions. Moreover, each module taught new knowledge and skills so that the course would remain resource intensive throughout. The instruction was text-based and included screen shots demonstrating how to perform techniques in Word. The Word documents used in the examples were provided for participants, and they were encouraged to practice as the techniques were demonstrated. The course was designed to take approximately five hours to complete, but participants controlled the pace of instruction - they determined the amount of time spent on each module and whether they completed the course in a single day or spread it out

\footnotetext{
${ }^{2}$ A survey at the end of the $10^{\text {th }}$ module asked participants whether they were aware of the purpose of the research. Two people accurately reported the purpose of the study and, consistent with the procedure employed in previous research (e.g., Stajkovic et al., 2006), they were dropped from all analyses. Thus, the analyses were run with the 616 people described in the participants section but the original sample size was 618 .
} 
over time. However, they were required to review the content in a predetermined order. After finishing each module, participants completed a multiple-choice test and received feedback on their performance.

\section{Manipulations}

Participants were randomly assigned to experimental conditions that differed in the pattern of subconscious and conscious goals across the 10 training modules. Thus, the design represents a 3 (subconscious goal: achievement, underachievement, no goal control condition) $\mathrm{x}$ 3 (conscious goal: difficult, easy, neutral goal control condition) x 10 modules repeated measures experimental design.

Subconscious goals. We supraliminally primed participants with images conveying achievement or underachievement due to evidence that pictures may serve as stronger primes than words. Glaser (1992) proposed that words must be processed by the lexical system before they can be processed by the semantic system, whereas pictures have a direct, functional connection to the semantic system. Paivio $(1986,1991)$ found pictures exert a greater effect on behavior than words. Also, from a practical standpoint, it is possible to prime employees with pictures in the work environment, whereas employees may find it unacceptable to be tasked with completing word games in an attempt to prime subconscious achievement goals (Shantz \& Latham, 2009).

Consistent with Stajkovic et al. (2006), subconscious achievement goals were primed through environmental cues related to prevailing, competing, accomplishing, striving, winning, and exerting effort. The achievement images were similar to those used in Latham's research (Latham \& Piccolo, 2012; Shantz \& Latham, 2009, 2011) and portrayed people exerting effort and attaining success. The images included cyclists racing up a hill, a swimmer celebrating in the 
water due to prevailing in a meet, and runners leaping across a finish line.

Subconscious underachievement goals were primed through environmental cues conveying laziness, slacking, drowsiness, lethargy, sluggishness, and sleepiness. The images used to prime underachievement included a man yawning and rubbing his eyes, a woman resting her head on her hand with eyes partially closed, and a man napping.

The no subconscious goal control condition did not contain images to prime subconscious goals. Thus, the only images on the slides were related to the content domain and consisted of screen shots demonstrating functions in Microsoft Word.

The primes were presented as small images in the corners of the slides and appeared on approximately 47 percent of the slides in a module. ${ }^{3}$ The achievement and underachievement primes were the same size and appeared in the same place on the slides. The same image was consistently used within a module, and the images differed across the 10 training modules.

Conscious goals. Participants were assigned a conscious difficult, easy, or neutral goal for each training module to ensure that the current study is parallel to Stajkovic et al. (2006). Before the first module, the following message appeared to inform participants that they would be assigned different goals for each module and to convince them that the goals are custom tailored to ensure their success in the course: Before each module, you will be given a goal. The goals will help you benefit from training as much as possible. The goals are based on your learning style, your performance as you go through training, and the content of each module. Therefore, the goals will change from module to module.

To increase the extent to which the subconscious and conscious goals were parallel,

\footnotetext{
${ }^{3}$ Prior research has not established an ideal percentage of content that should contain primed messages. For example, studies using words as primes generally contain between 50 and 70 percent primed words and between 30 and 50 percent neutral words (Latham et al., 2010; Stajkovic et al., 2006). We relied on a comparable percent of training slides that contained primed messages.
} 
conscious goals focused both on the level of effort that should be exerted and the performance standard participants should strive to attain. The difficult and easy goals were established based on time on task and test score data from a pilot study with 128 individuals who were recruited online in the same manner as the current study and participated in the same Microsoft Word course. The training modules differed in length and average test performance so the goals differed across modules. The difficult goals were approximately one standard deviation above the mean and the easy goals were approximately one standard deviation below the mean based on time on task and test scores among the pilot sample. Test scores and recommended minutes for reviewing were rounded up or down to whole numbers (e.g., 4 or 5 questions correct).

The difficult conscious goal assigned participants to answer between four and five out of six questions correct on the exam at the end of the module and spend between 30 and 72 minutes reviewing the material, depending on the module. It also informed them that the goal may be difficult to attain. For example, Your goal is to answer at least 4 out of 6 multiple-choice questions correct on the exam at the end of the next module. This goal may be difficult to attain so I recommend that you slow down and take your time reviewing the material. People who attain this goal typically spend more than 30 minutes reviewing the material in the next module.

The easy conscious goal assigned participants to answer between 2 and 3 out of 6 questions correct on the exam at the end of the module and spend between 15 and 36 minutes reviewing the material. Moreover, it informed them that the goal should be easy to attain. For example, Your goal is to answer at least 2 out of 6 multiple-choice questions correct on the exam at the end of the next module. This goal should be easy to attain so feel free to review the material as quick as possible and save your time for subsequent modules. People who attain this goal typically spend less than 15 minutes reviewing the material in the next module. 
The neutral conscious goal was the same across training modules, Do your best on the exam at the end of the next module. Take as much time as necessary reviewing the material. ${ }^{4}$

\section{Measures}

Demographics were assessed pretraining. Time spent reviewing the course material and goal abandonment were captured by the LMS.

Time on task. Time on task represents the amount of time spent reviewing the course material. On average, participants devoted between 0.36 and 0.66 hours per module.

Task performance. Six item multiple-choice exams were administered at the conclusion of each module. Test scores ranged from an average of 45 to 66 percent correct per module and individual performance ranged from 0 to 100 percent correct.

Goal abandonment. Of the 616 participants who started the course, 307 (50\%) dropped out in module 1, $101(16 \%)$ dropped out in module 2, $29(5 \%)$ dropped out in module 3, and 34 (6\%) dropped out in module 4. The attrition rate declined in subsequent modules, such that between 0 and 4 percent of participants dropped out in each of modules 5 through 10. Overall, 76 (12\%) participants completed the course. This is similar to the 82 to 95 percent attrition rate observed from over 3.5 million individuals who have participated in more than 6,000 voluntary online courses (Korn \& Levitz, 2013).

\section{Data Analysis}

Hierarchical linear modeling (HLM) with full maximum likelihood estimates was used to analyze the within-person results for the continuous outcomes_-time on task and task

\footnotetext{
${ }^{4}$ Nine experimental conditions were created for this research because the number of possible experimental conditions with 10 modules and two manipulations with three levels each is $3,486,784,401$. With three levels of the subconscious goals manipulation and three levels of the conscious goals manipulation, there were nine possible combinations of goals that could appear in any module. The nine experimental conditions differed in the order that individuals viewed the subconscious and conscious goals, but each condition contained all nine possible combinations of subconscious and conscious goals.
} 
performance - to account for the fact that repeated measures were nested within participants. SAS PROC MIXED was used to run the analyses following the model building procedure specified by Bliese and Ployhart (2002). Hierarchical generalized linear modeling (HGLM) was used to predict goal abandonment. Generalized linear models are extensions of mixed-effect models to cases where standard linear modeling assumptions are violated (Littell, Milliken, Stroup, Wolfinger, \& Schabenberger, 2006). We ran the analyses with SAS PROC GLIMMIX following the procedure outlined by Littell et al. (2006) and Raudenbush and Bryk (2002). In each of the analyses, module was included as a covariate because time dependent analyses can be sensitive to order effects. Module was coded $0,1 \ldots 8,9$ so that the intercept represents scores in module 1 . Goal setting was dummy coded to compare subconscious achievement and underachievement goals (each coded 1) to the no subconscious goal control condition (coded 0) as well as difficult and easy conscious goals (each coded 1) to the neutral conscious goal control condition (coded 0). Bliese (2002) and Hofmann and Gavin (1998) state that the centering technique employed must be driven by the theoretical model. We grand mean centered time on task and task performance because the self-regulated learning literature has demonstrated theoretical and empirical effects of effort on task performance (Sitzmann \& Ely, 2010, 2011; Yeo \& Neal, 2004) and task performance on goal abandonment (Robbins et al., 2004; Sitzmann et al., 2010; Sitzmann \& Johnson, 2012b) at both the within- and betweenperson levels of analysis. In addition to the effects reported on the tables, we ran the analyses with the mean entered as a level-2 predictor and found the effect sizes and significance of the results were unaffected by this change. Specifically, controlling for the average time on task did not affect the results predicting task performance and controlling for the average task performance did not affect the results predicting goal abandonment. This lends further 
confidence in the results, alleviating the concern that grand mean centering can produce confounded estimates of mediation effects (Zhang, Zyphur, \& Preacher, 2009).

Goal abandonment was coded such that individuals received a 0 in modules that they completed and a 1 in the module where they dropped out. Data were missing after individuals dropped out because goal abandonment precludes collecting information regarding how individuals would have responded in subsequent modules. The appendix clarifies the pattern of conscious and subconscious goals and sample sizes across experimental conditions and training modules.

Past behavior is one of the strongest predictors of future behavior (Ouellette \& Wood, 1998). Further, there is substantial variability in the amount of effort exerted to learn the course material and perform well on performance assessments in voluntary online training (Sitzmann \& Johnson, 2012a). For example, individuals spent between 11 seconds (suggesting that they randomly responded) and 21.7 minutes responding to the exam questions across performance assessments $($ Mean $=4.65$ minutes, $S D=2.39)$. Individuals also devoted between 24 seconds (suggesting that they decided it was unnecessary to allocate resources to the current module) and 2.92 hours reviewing across modules $($ Mean $=0.49$ hours, $S D=0.43)$. Thus, we controlled for the amount of time devoted to the exams in the analyses predicting task performance and prior time on task in the analyses predicting time on task. Controlling for the amount of time devoted to the exams verifies that the effect of subconscious goals on task performance is due to individuals' understanding of the course content rather than whether they took sufficient time to read and process the exam questions.

We used one-tailed tests of significance for the hypothesized effects due to the directional nature of the hypotheses, the high measurement error typical of field research, and the reduced 
statistical power caused by the high attrition rate. Two-tailed tests were used for non-

hypothesized effects. One of the advantages of HLM and HGLM with a repeated measures

design is the robustness of calculating parameters with all available data, despite missing data

(Bryk \& Raudenbush, 1992; Ployhart, Holtz, \& Bliese, 2002). Thus, it is unnecessary to use

listwise deletion or data imputation to deal with missing data. Rather, the analyses were run

using data from the modules that individuals completed before abandoning their goal. ${ }^{5}$

\section{Results}

Intraclass correlation coefficients, descriptive statistics, and correlations among study

variables at the within- and between-person levels of analysis are presented in Table 1. Next, we review each of the study hypotheses and their corresponding results (see Table 2).

\section{Subconscious Achievement Goals and Task Performance}

The first hypothesis predicts that subconscious achievement goals have a positive withinperson effect on time on task, relative to the no subconscious goal condition. Supporting this prediction, individuals spent 9 percent more time on task when primed with achievement goals than in modules where their subconscious goals were not primed $(\Upsilon=0.03, p<.05)$.

According to Hypothesis 2, subconscious achievement goals have a more positive effect on task performance when conscious goals are neutral rather than difficult. Subconscious

\footnotetext{
${ }^{5}$ Missing data can be ignored if it meets Rubin's (1976) missing at random assumption, meaning dropout is random. However, we hypothesize that subconscious underachievement goals predict goal abandonment, suggesting that data is not missing at random. Thus, we used a pattern-mixture model for missing data, following the procedure outlined by Hedeker and Gibbons (1997) and Sitzmann et al. (2010). Pattern-mixture models divide subjects into groups depending on their missing data pattern and test whether the grouping variable affects the results. In the current research, we created a completion status variable indicating whether individuals completed the course (coded 0) or dropped out before completing the course (coded 1). Completion status was then added as a main effect and we tested the interaction between completion status and both subconscious and conscious goals when predicting time on task and task performance. This permits examining whether the effects of the goal conditions differ for individuals who completed the course and those who abandoned their goal. The results revealed that completion status did not significantly interact with subconscious or conscious goals when predicting time on time on task or task performance. This lends credence to the results and suggests that goal abandonment did not affect the robustness of the maximum likelihood estimates.
} 
achievement goals interacted with conscious difficult and easy goals $(\Upsilon=-0.05 \&-0.05$, respectively, $p<.05)$. Subconscious achievement goals had a more positive effect on task performance (relative to the no prime control condition) when conscious goals asked individuals to do their best than when they were assigned difficult or easy conscious goals (see Figure 2). These results support Hypothesis 2.

Hypothesis 3 suggests that the positive effect of time on task on performance is stronger when conscious goals are neutral rather than difficult. The difficult conscious goal by time on task interaction was significant $(\Upsilon=0.06, p<.05)$. However, time on task had a more positive effect on task performance when conscious goals were difficult rather than neutral, which is opposite the prediction set forth in Hypothesis 3 (Figure 3). It is also important to note that the conscious difficult goal by subconscious achievement goal interaction (Hypothesis 2) was reduced in magnitude and no longer significant when the conscious difficult goal by time on task interaction was added to the equation, suggesting that the interaction is mediated.

Overall, this suggests that a 9 percent increase in resource allocation due to subconscious achievement goals is sufficient for producing meaningful change in performance as long as conscious goals remain neutral. Yet, overcoming the obstacle of regulating difficult conscious goals during skill acquisition necessitates a substantial surge in resource allocation, such that the one standard deviation increase in time on task depicted in Figure 3 represents an 88 percent increase in resource allocation, relative to the mean. The potential implications of these findings will be examined in the Discussion section. ${ }^{6}$

\footnotetext{
6 To confirm that the interactions occurred at the hypothesized stages of the model, we also tested for the interaction between subconscious and conscious goals when predicting time on task (i.e., first stage moderation) and whether the indirect effect from subconscious achievement goals to task performance is moderated by conscious goal setting. The subconscious achievement by conscious difficult goals interaction was not significant when predicting time on task $(\Upsilon=-0.01, p>.10)$. Further, the indirect effect of subconscious achievement goals on task performance was the same for neutral $(0.00, p>.10)$ and difficult $(0.00, p>.10)$ conscious goals. These findings provide additional
} 
Finally, we ran a post hoc analysis to examine whether subconscious achievement goals have an indirect effect on goal abandonment via task performance. We followed the procedure outlined by Edwards and Lambert (2007) and found that the indirect effect of subconscious achievement goals on goal abandonment was nonsignificant $(\Upsilon=0.03, p>.05)$, as was the indirect effect of neutral subconscious goals on goal abandonment $(\Upsilon=0.01, p>.05)$.

\section{Subconscious Underachievement Goals and Goal Abandonment}

Hypothesis 4 predicts that subconscious underachievement goals have a positive withinperson effect on goal abandonment, relative to the no subconscious goal control condition. The probability of goal abandonment was 3.7 percentage points higher in modules where individuals were primed with underachievement goals than in modules where subconscious goals were not primed (logit $=0.26, p<.05)$, supporting Hypothesis 4 .

Next, we tested Hypothesis 5-subconscious underachievement goals have a negative within-person effect on task performance and performance mediates the subconscious underachievement goal to goal abandonment relationship. Consistent with the hypothesis, test scores were 5.9 percent lower when individuals were primed with underachievement goals than when their subconscious goals were not primed $(\Upsilon=-0.03, p<.05)$. Moreover, prior task performance had a negative effect on goal abandonment, such that the probability of goal abandonment was 6.9 percentage points greater following low than high performance when comparing test scores one standard deviation above and below the mean (logit $=-1.10, p<.05)$. The logit for subconscious underachievement goals was reduced in magnitude and no longer significant when prior performance was included in the analysis. Thus, task performance mediates the effect of subconscious underachievement goals on goal abandonment, supporting 


\section{Hypothesis $5 .^{7}$}

The sixth hypothesis predicts that subconscious underachievement goals have a more negative effect on task performance when conscious goals are neutral rather than difficult. Subconscious underachievement goals significantly interacted with conscious difficult goals when predicting performance $(\Upsilon=0.07, p<.05)$. Consistent with the hypothesis, subconscious underachievement goals had a more negative effect on task performance (relative to the no prime condition) when individuals were assigned neutral conscious goals than when they were assigned difficult conscious goals (see Figure 2).

Finally, Hypothesis 7 predicts that difficult conscious goals exacerbate the negative effect of task performance on goal abandonment. Prior performance interacted with both difficult and easy conscious goals when predicting goal abandonment (logit $=-2.17 \&-1.75$, respectively, $p<$ .05). When conscious goals were neutral, the probability of dropping out was similar following low and high performance (see Figure 4). However, the probability of dropping out was 13.4 percentage points greater following low than high performance when conscious goals were difficult and 8.7 percentage points greater following low than high performance when conscious goals were easy. Thus, the results support Hypothesis 7. ${ }^{8,9}$

\footnotetext{
${ }^{7}$ We ran post hoc analyses to examine carryover effects from the primes in the prior trial on time on task, task performance, and goal abandonment. The primes in the prior trial did not have a significant main effect on time on task nor task performance. However, subconscious underachievement goals increased the risk of goal abandonment in the subsequent as well as the current module (logit for subconscious underachievement goals in the prior module $=0.50$ while controlling for subconscious and conscious goals in the current module as well as prior task performance, $p<.05$ ).

${ }^{8}$ Goal commitment was measured immediately after presenting individuals with their goal for a module and was assessed with two items-I am committed to attaining this goal and I will do my best to achieve this goal-and a five-point Likert scale ranging from strongly disagree to strongly agree. Individuals nearly uniformly committed to their assigned goals with a mean across the training modules of $4.44(S D=0.81)$ and responses of agree or strongly agree $91 \%$ of the time. Moreover, adding goal commitment to the analyses did not change the results, possibly due to the lack of variability in commitment. Specifically, adding goal commitment to the analyses did not result in external goals having a significant main effect on any of the outcome variables and goal commitment did not significantly interact with conscious goals when predicting any of the outcome variables.

9 To confirm that the interactions occurred at the hypothesized stages of the model, we also tested for the interaction between subconscious and conscious goals when predicting goal abandonment and whether the indirect effect from
} 


\section{Discussion}

Wilson (2002) proposed that the human mind can take in 11 million pieces of information at any given moment, but people are only consciously aware of 40 of these. This is consistent with Bargh's (1997) claim that at least 99\% of psychological reactions are automatically activated. Thus, the subconscious mind is responsible for processing the vast majority of the information that we encounter on a daily basis (Baumeister, Bratslavsky, Muraven, \& Tice, 1998).

These claims point to the need for a theoretical account of the role of the subconscious in guiding goal striving behavior. This study begins to address calls for a theory of subconscious goals (Lord, Diefendorff, Schmidt, \& Hall, 2010; Stajkovic et al., 2006) and builds on research in social psychology, which has primarily focused on simple behavior that may not generalize to organizational settings (Latham et al., 2010). Specifically, we advance research on subconscious goals by expanding both the predictor and criterion space to focus on subconscious underachievement as well as achievement goals and examining the effects of these goals on resource allocation, task performance, and goal abandonment. Moreover, we employ a withinperson design to examine how individuals respond to changing environmental stimuli as their cognitive resources are taxed by situational demands. Examining subconscious goals at the within-person level of analysis is consistent with evidence that both primed messages in work environments and goal striving behavior are dynamic and vary considerably over time (Bargh et al., 2001; Chartrand \& Bargh, 2002; Schmidt \& DeShon, 2007).

subconscious underachievement goals to goal abandonment is moderated by conscious goal setting. There was not a significant subconscious underachievement by conscious difficult goals interaction when predicting goal abandonment $(\operatorname{logit}=-0.11, p>.10)$. Further, the indirect effect of subconscious underachievement goals on goal abandonment was the same for neutral $(-0.01, p>.10)$ and difficult $(-0.01, p>.10)$ conscious goals. These findings provide additional support for the hypothesized subconscious underachievement goals model (see Figure 1) and are consistent with a first and second stage moderation model (Edwards \& Lambert, 2007). 


\section{Subconscious Achievement Goals and Task Performance}

Subconscious achievement goals enhance knowledge and skill acquisition. In particular, priming achievement increased the amount of time devoted to skill acquisition and led to higher performance when conscious goals were neutral. In fact, the combination of a subconscious achievement goal and a neutral conscious goal produced the highest performance of any condition (see Figure 2). However, when subconscious achievement goals were combined with difficult or easy conscious goals, performance was significantly lower. This finding suggests that specific conscious goals, regardless of their difficulty, undermine the performance benefits associated with subconscious achievement goals, likely because they require individuals to redirect resources toward monitoring goal progress. Some support for this rationale is provided by the significant interaction between conscious goals and time on task, which revealed that individuals were able to achieve high performance when given difficult conscious goals if they devoted substantial time to skill acquisition (see Figure 3). Allocating more time to skill acquisition may enable individuals to overcome the cognitive demands of dividing attentional resources between regulating goal pursuit and skill acquisition and, therefore, benefit from the high standard set by difficult conscious goals. Yet, as noted earlier, a substantial increase in resource allocation ( 88 percent relative to the mean) was required to overcome the challenges associated with regulating difficult conscious goals. This suggests that a more efficient path to high performance is to provide individuals with subconscious achievement goals and neutral conscious goals. Under these conditions, a much smaller increase in resource allocation (9 percent on average) was sufficient to yield high performance.

In summary, the most effective approach to skill acquisition is to relegate goal pursuit to the subconscious because subconscious achievement goals facilitate task performance via 
increased resource allocation. Difficult conscious goals can also enhance task performance as long as significant time is set aside to unleash the motivational potential of pursuing difficult conscious goals during skill acquisition.

\section{Subconscious Underachievement Goals and Goal Abandonment}

Our findings suggest that subconscious underachievement goals initiate a downward spiral in which task performance is impaired and the risk of goal abandonment is heightened. Exposure to underachievement images has a powerful impact on behavior. It is challenging to attain one's full potential in the presence of messages conveying laziness, sluggishness, and listlessness because these messages trigger underachievement motivation.

Yet, whether subconscious underachievement goals led to low performance and low performance led to goal abandonment was contingent upon the timing of implementation and difficulty of conscious goals. When difficult performance goals were implemented before individuals experienced poor performance, difficult conscious goals reduced the deleterious effect of subconscious underachievement goals on task performance (relative to when conscious goals were neutral; see Figure 2). This suggests that difficult conscious goals may help to neutralize the negative effect of underachievement environmental stimuli as long as they are implemented before these stimuli have begun to impair performance.

However, if conscious goals were established after performance was undermined, difficult conscious goals exacerbated the effect of task performance on goal abandonment (see Figure 4). Individuals are likely to abandon a goal when they perceive that the discrepancy between their current state and their goal is sufficiently large to preclude goal attainment (Vancouver, 2000). Task performance is an integral component of this process (Sitzmann et al., 2010). High performance suggests that individuals are on track to attain content mastery, thereby 
increasing motivation, commitment to skill acquisition, and task persistence (Frese \& Zapf, 1994; Sitzmann \& Johnson, 2012a). Poor performance suggests that learning is deficient and individuals are not benefitting from the time they are investing in skill acquisition (Sitzmann et al., 2010). Moreover, poor performance in concert with a difficult conscious goal makes goal attainment nearly impossible, resulting in a high probability of goal abandonment.

In summary, our findings reveal that environmental messages can trigger underachievement goals and these goals can undermine performance and induce goal abandonment. Difficult conscious goals may neutralize the effects of implicit underachievement but only when implemented before individuals are locked into a downward spiral of poor performance.

\section{Practical Implications}

Subtle environmental cues trigger subconscious achievement and underachievement motivation. Thus, it is essential that organizations foster an environment where employees are regularly exposed to messages throughout the workday that convey information related to exerting effort, succeeding, and prevailing as these messages enhance resource allocation and task performance. It is equally important for organizations to minimize messages conveying laziness, sluggishness, and slacking from work. These messages are incredibly toxic in that they undermine task performance and increase the probability of goal abandonment. In situations where employees are likely to encounter these messages, organizations can use challenging conscious goals to counteract the detrimental effects of subconscious underachievement goals.

Organizations can deliver achievement-related messages through a variety of mechanisms, including leader communication, newsletters, and online media. In 2011, for example, Corning Incorporated developed an online video titled A Day Made of Glass to feature 
the company's innovations in specialty glass and to present a vision for how its technologies can help shape the world. Similarly, General Electric recently launched a campaign titled GE Works in which television commercials, online videos, and stories posted on the corporate website advertise the organization's achievements and the role that GE employees played in attaining those successes. Likewise, McKesson Corporation created a Vision Center to showcase its successful products and services and their role in transforming patient-centered healthcare. In addition to such elaborate measures, our results suggest that organizations can use imagery in the workplace (e.g., pictures of pioneering employees or successful products) to convey messages related to achievement and success.

It is also important to consider when it is best to employ subconscious goals, conscious goals, or both types of goals. Our results suggest that when individuals are striving to attain subconscious achievement goals, conscious goals should remain neutral to maximize skill acquisition. However, this recommendation may only apply to complex tasks that place significant demands on attentional resources. On simpler tasks, there may be sufficient resources available to leverage the joint benefits of subconscious achievement and difficult conscious goals. Indeed, Stajkovic et al. (2006) found that subconscious achievement goals enhanced the effect of difficult conscious goals on performance during a brainstorming task. Our results further suggest that when individuals have been exposed to environmental cues that convey underachievement, conscious difficult goals should be established to mitigate the effects of subconscious underachievement goals on task performance and goal abandonment. One caveat to this rule is that difficult conscious goals must be established before subconscious underachievement goals undermine performance. If performance has already been undermined, difficult conscious goals exacerbate the deleterious effect of subconscious underachievement 
goals on goal abandonment.

The priming manipulations in the current and prior research were implemented without alerting participants to the fact that researchers were attempting to alter their behavior. This raises serious ethical considerations that must be addressed before subconscious processes can be primed in the workplace. Foremost, trust may be grievously impaired if employees became aware that management was attempting to manipulate their behavior without their consent (White \& Locke, 2000). Yet, informing employees that they are being primed could potentially mitigate priming effects (Stajkovic et al., 2006). Second, management may not uniformly utilize priming to enhance performance, and could potentially undermine performance with subconscious underachievement goals. Thus, research needs to address whether the implications of altering employees' behavior without their consent outweigh the benefits of enhancing performance with subconscious achievement goals.

\section{Study Limitations and Directions for Future Research}

At the end of priming experiments, participants are traditionally quizzed regarding whether they were aware of the experimental manipulation or the fact that they were primed. Typically less than 10 percent of participants have reported any awareness of the primes and data from those participants was discarded (Bargh \& Chartrand, 2000; Chartrand \& Bargh, 2002; Shantz \& Latham, 2009, 2011; Stajkovic et al., 2006). In the current study, only three percent of individuals who completed the course reported awareness of the experimental manipulation, but it is possible that those who dropped out earlier were aware that they were being primed. Research is needed to establish whether awareness of priming alters its effects and, thus, whether it is necessary to discard data from participants who report knowledge of the experimental manipulation. 
It is important to note that conscious goal setting did not have a main effect on time on task, task performance, or goal abandonment, and the current results apply to conscious performance (but not conscious learning) goals. Difficult conscious goals requested that individuals devote substantial time to skill acquisition, and the motivational power of these goals was only realized when individuals followed these instructions. This explains why individuals performed at the same level, on average, when their conscious goals were difficult, easy, or neutral and subconscious goals were not primed (see Figure 2). The crux of this effect is resource allocation — when individuals devoted a little or a moderate amount of time to skill acquisition, performance was similar regardless of goal difficulty. Yet, at high levels of resource allocation, individuals performed better if they were striving toward difficult rather than neutral conscious goals. Allocating substantial time to skill acquisition may enable overcoming the cognitive demands of dividing information processing resources between regulating goal pursuit and skill acquisition and, therefore, benefitting from the high standard set by difficult conscious goals.

We did not test for one of the key mediators - information processing capacityunderlying the hypothesized effects. This is an inherent limitation of subconscious goals research; their presumed benefits are that they operate outside conscious awareness and are effective when information processing resources are taxed, but testing for information processing capacity is challenging and cannot be done as people are participating in training. DeShon, Brown, and Greenis (1996) tested how conscious goals operate when information processing resources are taxed, but their research took place in a laboratory setting where people were required to complete multiple tasks simultaneously to ensure that working memory was operating at maximum capacity. Subconscious goals should be tested with a similar paradigm to verify that information processing capacity is a valid explanation for their adaptive nature. 
Related, the current research relied on a global measure of time on task that obscured whether individuals were concentrating mental resources on learning or engaging in off-task thoughts. To gain further insight into how subconscious goals affect proximal and distal self-regulatory processes, future research should explore new methods that may enable direct measurement of resource allocation. Ashkanasy, Becker, and Waldman (2014), for example, argue that neuroscience holds significant promise for testing hypotheses about previously unobservable mental processes.

Chen and Latham (2014) is the only study aside from the current research that has examined the effects of subconscious goals utilizing a repeated measures design. Yet, research on conscious goal setting and self-regulation illustrates that "multiple goals and conflicting priorities are a way of life in the modern workplace" and increasing goal difficulty necessitates that resources are pulled away from one activity and redirected toward attaining challenging goals (Schmidt \& DeShon, 2007, p. 928). Moreover, the current research highlights that individuals' subconscious goals interacted with their prior performance when deciding whether to persist or abandon training, which would have been overlooked by employing a betweenperson design. Thus, future research should examine how employees regulate training engagement along with competing demands in their work and personal lives, necessitating a dynamic perspective that accounts for the complex array of tasks that employees juggle throughout the day (Sitzmann \& Weinhardt, in press).

It is also important to acknowledge that conscious learning goals do not tax information processing resources to the same degree as conscious performance goals (Locke \& Latham, 2002). Furthermore, Chen and Latham (2014) found subconscious learning goals—-but not subconscious performance goals - enhanced performance on a complex task that required skill 
acquisition. Thus, future research should examine the joint effects of subconscious and conscious forms of both performance and learning goals as well as mediators of goals' effects to develop a comprehensive theory of the conditions under which goal setting should be relegated to the subconscious, conscious information processing, or both. Carefully tailoring the work environment with messages related to achievement while eradicating messages related to underachievement may hold the key to ensuring employees consistently exert effort and excel at goal attainment. 


\section{References}

Aarts, H., \& Dijksterhuis, A. (2003). The silence of the library: environment, situational norm, and social behavior. Journal of Personality and Social Psychology, 84(1), 18.

Aarts, H., Gollwitzer, P. M., \& Hassin, R. R. (2004). Goal contagion: Perceiving is for pursuing. Journal of Personality and Social Psychology, 87(1), 23-37.

Ashkanasy, N. M., Becker, W. J., \& Waldman, D. A. (2014). Neuroscience and organizational behavior: Avoiding both neuro-euphoria and neuro-phobia. Journal of Organizational Behavior, 35, 909-919.

Bandura, A. (1991). Social-cognitive theory of self-regulation. Organizational Behavior and Human Decision Processes, 50(2), 248-287.

Bargh, J. A. (1990). Goal $\neq$ intent: Goal-directed thought and behavior are often unintentional. Psychological Inquiry, 1(3), 248-251.

Bargh, J. A. (1997). The automaticity of everyday life. In R. Wyer Jr. (Ed.), The automaticity of everyday life: Advances in social cognition (Vol. 10, pp. 1-61). Mahwah, NJ: Lawrence Erlbaum Associates, Inc.

Bargh, J. A., \& Chartrand, T. L. (2000). Studying the mind in the middle: A practical guide to priming and automaticity research. In H. Reis \& C. Judd (Eds.), Handbook of Research Methods in Social Psychology (pp. 253-285). New York, NY: Cambridge University Press.

Bargh, J. A., Chen, M., \& Burrows, L. (1996). Automaticity of social behavior: Direct effects of trait construct and stereotype activation on action. Journal of Personality and Social Psychology, 71(2), 230-244.

Bargh, J. A., Gollwitzer, P. M., Lee-Chai, A., Barndollar, K., \& Trötschel, R. (2001). The automated will: Nonconscious activation and pursuit of behavioral goals. Journal of Personality and Social Psychology, 81(6), 1014-1027. 
Baumeister, R. F., Bratslavsky, E., Muraven, M., \& Tice, D. M. (1998). Ego depletion: Is the active self a limited resource? Journal of Personality and Social Psychology, 74(5), 1252-1265.

Beal, D. J., Weiss, H. M., Barros, E., \& MacDermid, S. M. (2005). An episodic process model of affective influences on performance. Journal of Applied Psychology, 90, 1054-1068.

Bliese, P. D. (2002). Using multilevel random coefficient modeling in organizational research. In F. Drasgow \& N. W. Schmitt (Eds.), Advances in measurement and data analysis (pp. 401-445). San Francisco, CA: Jossey-Baas.

Bliese, P. D. \& Ployhart, R. E. (2002). Growth modeling using random coefficient models: Model building, testing, and illustrations. Organizational Research Methods, 5(4), 362387.

Bryk, A. S., \& Raudenbush, S. W. (1992). Hierarchical linear models in social and behavioral research: Applications and data analysis methods (First Edition). Newbury Park, CA: Sage Publications.

Carter, J. A., McNair, L. D., Corbin, W. R., \& Black, D. H. (1998). Effects of priming positive and negative outcomes on drinking responses. Experimental and Clinical Psychopharmacology, 6, 399-405.

Carver, C. S., \& Scheier, M. F. (1998). On the self-regulation of behavior. New York, NY: Cambridge University Press.

Carver, C. S., \& Scheier, M. F. (2000). Scaling back goals and recalibration of the affect system are processes in normal adaptive self-regulation: Understanding 'response shift' phenomena. Social Science \& Medicine, 50, 1715-1722.

Chartrand, T. L., \& Bargh, J. A. (2002). Nonconscious motivations: Their activation, operation, and consequences. In A. Tesser, D. Stapel \& J. Woods (Eds.), Self and motivation: Emerging psychological perspectives (pp. 13-41). Washington, DC: American 
Psychological Association.

Chartrand, T. L., Maddux, W. W., \& Lakin, J. L. (2005). Beyond the perception-behavior link: The ubiquitous utility and motivational moderators of nonconscious mimicry. In R. Hassin, J. Uleman \& J. Bargh (Eds.), The New Unconscious (pp. 334-361). New York, NY: Oxford University Press.

Chen, X., \& Latham, G. P. (2014). The effect of priming learning vs. performance goals on a complex task. Organizational Behavior and Human Decision Processes, 125, 88-97.

Cheng, C. M., \& Chartrand, T. L. (2003). Self-monitoring without awareness: Using mimicry as a nonconscious affiliation strategy. Journal of Personality and Social Psychology, 85(6), 1170.

Collins, C. J., Hanges, P. J., \& Locke, E. A. (2004). The relationship of achievement motivation to entrepreneurial behavior: A meta-analysis. Human Performance, 17(1), 95-117.

DeShon, R. P., Brown, K. G., \& Greenis, J. L. (1996). Does self-regulation require cognitive resources? Evaluation of resource allocation models of goal setting. Journal of Applied Psychology, 81(5), 595-608.

Dijksterhuis, A. (2014). Welcome back theory! Perspectives on Psychological Science, 9(1), 7275.

Dishon-Berkovits, M. (2014). A study of motivational influences on academic achievement. Social Psychology of Education, 17(2), 327-342.

Edwards, J. R., \& Lambert, L. S. (2007). Methods for integrating moderation and mediation: A general analytical framework using moderated path analysis. Psychological Methods, 12, $1-22$.

Frese, M., \& Zapf, D. (1994). Action as the core of work psychology: A German approach. In M. Dunnette, L. Hough \& H. Triandis (Eds.), Handbook of Industrial and Organizational Psychology (Vol. 4, pp. 271-340). Palo Alto, CA: Consulting Psychologists Press. 
Glaser, B. (1992). Basics of grounded theory analysis. Mill Valley, CA: Sociology Press.

Gollwitzer, P. M., \& Bargh, J. A. (1996). The psychology of action: Linking cognition and motivation to behavior. New York, NY: Guilford Press.

Hedeker, D., \& Gibbons, R. D. (1997). Application of random effects pattern-mixture models for missing data in longitudinal studies. Psychological Methods, 2, 64-78.

Hofmann, D. A., \& Gavin, M. B. (1998). Centering decisions in hierarchical linear models: Implications for research in organizations. Journal of Management, 24(5), 623-641.

Kanfer, R., \& Ackerman, P. L. (1989). Motivation and cognitive abilities: An integrative/aptitude-treatment interaction approach to skill acquisition. Journal of Applied Psychology, 74, 657-690.

Kanfer, R., Ackerman, P. L., Murtha, T. C., Dugdale, B., \& Nelson, L. (1994). Goal setting, conditions of practice, and task performance: A resource allocation perspective. Journal of Applied Psychology, 79, 826-835.

Korn, M., \& Levitz, J. (2013). Online courses look for a business model. The Wall Street Journal, p. B8.

Köpetz, C., Faber, T., Fishbach, A., \& Kruglanski, A. W. (2011). The multifinality constraints effect: How goal multiplicity narrows the means set to a focal end. Journal of Personality and Social Psychology, 100(5), 810-826. doi:10.1037/a0022980

Kruglanski, A. W., Shah, J. Y., Fishbach, A., Friedman, R., Chun, W. Y., \& SleethKeppler, D. (2002). A theory of goal systems. Advances in Experimental Social Psychology, 34, 331-378.

Latham, G. P., \& Piccolo, R. F. (2012). The effect of context-specific versus nonspecific subconscious goals on employee performance. Human Resource Management, 51(4), 
535-548.

Latham, G. P., Stajkovic, A. D., \& Locke, E. A. (2010). The relevance and viability of subconscious goals in the workplace. Journal of Management, 36(1), 234-255.

Légal, J. B., Meyer, T., \& Delouveé, S. (2007). Effect of compatibility between conscious goal and nonconscious priming on performance. Current Research in Social Psychology, 12(6), 81-90.

Littell, R. C., Milliken, G. A., Stroup, W. W., \& Wolfinger, R. D., \& Schabenberger, O. (2006). SAS for mixed models. (2nd ed.). Cary, NC: SAS Institute, Inc.

Locke, E. A. (2007). The Case for Inductive Theory Building†. Journal of Management, 33(6), 867-890.

Locke, E. A., \& Latham, G. P. (1990). A theory of goal setting \& task performance. Englewood Cliffs, NJ: Prentice-Hall.

Locke, E. A., \& Latham, G. P. (2002). Building a practically useful theory of goal setting and task motivation: A 35-year odyssey. American Psychologist, 57, 705-717.

Lord, R. L., Diefendorff, J. M., Schmidt, A. M., \& Hall, R. J. (2010). Self-regulation at work. Annual Review of Psychology, 61, 543-568.

Lord, R. G., \& Levy, P. E. (1994). Moving from cognition to action: A control theory perspective. Applied Psychology: An International Review, 43, 335-398.

Masuda, A. D., Locke, E. A., \& Williams, K. J. (2015). The effects of simultaneous learning and performance goals on performance: An inductive exploration. Journal of Cognitive Psychology, 27(1), 37-52.

Meltzoff, A. N., \& Moore, M. K. (1997). Explaining facial imitation: A theoretical model. Early Development \& Parenting, 6(3-4), 179.

Nahrgang, J. D., DeRue, D. S., Hollenbeck, J. R., Spitzmuller, M., Jundt, D. K., \& Ilgen, D. R. (2013). Goal setting in teams: The impact of learning and performance goals on process 
and performance. Organizational Behavior and Human Decision Processes, 122(1), 1221.

Ordóñez, L. D., Schweitzer, M. E., Galinsky, A. D., \& Bazerman, M. H. (2009). Goals gone wild: The systematic side effects of overprescribing goal setting. Academy of Management Perspectives, 23 (1), 6-16.

Ouellette, J.A., \& Wood W. (1998). Habit and intention in everyday life: the multiple processes by which past behavior predicts future behavior. Psychological Bulletin, 124, 54-74.

Paivio, A. (1986). Mental representations: A dual coding approach. New York, NY: Oxford University Press.

Paivio, A. (1991). Dual coding theory: Retrospect and current status. Canadian Journal of Psychology, 45(3), 255-287.

Payne, J. W., Samper, A., Bettman, J. R., \& Luce, M. F. (2008). Boundary conditions on unconscious thought in complex decision making. Psychological Science, 19(11), 11181123.

Ployhart, R. E., Holtz, B. C., \& Bliese, P. D. (2002). Longitudinal data analysis: Applications of random coefficient modeling to leadership research. The Leadership Quarterly, 13(4), 455-486.

Raudenbush, S. W., \& Bryk, A. S. (2002). Hierarchical linear models: Applications and data analysis methods. (2nd ed.). Thousand Oaks, CA: Sage Publications.

Robbins, S. B., Lauver, K., Le, H., Davis, D., Langley, R., \& Carlstrom, A. (2004). Do psychosocial and study skill factors predict college outcomes? A metaanalysis. Psychological Bulletin, 130(2), 261.

Rubin, D. B. (1976). Inference and missing data. Biometrika, 63, 581-592.

Schmidt, A. M., \& DeShon, R. P. (2007). What to do? the effects of discrepancies, incentives, and time on dynamic goal prioritization. Journal of Applied Psychology, 92(4), 928-941. 
Schmidt, A. M., \& Dolis, C. M. (2009). Something's got to give: The effects of dual-goal difficulty, goal progress, and expectancies on resource allocation. Journal of Applied Psychology, 94(3), 678-691.

Schultheiss, O. C., \& Brunstein, J. C. (2001). Assessment of implicit motives with a research version of the TAT: Picture profiles, gender differences, and relations to other personality measures. Journal of Personality Assessment, 77(1), 71-86.

Schultheiss, O. C., \& Brunstein, J. C. (Eds.). (2010). Implicit motives. Oxford University Press.

Shah, J. Y., Friedman, R., \& Kruglanski, A. W. (2002). Forgetting all else: On the antecedents and consequences of goal shielding. Journal of Personality and Social Psychology, 83(6), 1261-1280. doi:10.1037//0022-3514.83.6.1261

Shantz, A., \& Latham, G. P. (2009). An exploratory field experiment of the effect of subconscious and conscious goals on employee performance. Organizational Behavior and Human Decision Processes, 109(1), 9-17.

Shantz, A., \& Latham, G. P. (2011). The effect of primed goals on employee performance: Implications for human resource management. Human Resource Management, 50(2), 289-299.

Sitzmann, T., \& Ely, K. (2010). Sometimes you need a reminder: The effects of prompting selfregulation on regulatory processes, learning, and attrition. Journal of Applied Psychology, 95, 132-144.

Sitzmann, T., \& Ely, K. (2011). A meta-analysis of self-regulated learning in work-related training and educational attainment: What we know and where we need to go. Psychological Bulletin, 137(3), 421-442. 
Sitzmann, T., Ely, K., \& Bell, B. S., \& Bauer, K. N. (2010). The effects of technical difficulties on learning and attrition during online training. Journal of Experimental Psychology: Applied, 16, 281-292.

Sitzmann, T. \& Johnson, S. K. (2012a). When is ignorance bliss? The effects of inaccurate selfassessments of knowledge on learning and attrition. Organizational Behavior and Human Decision Processes, 117(1), 192-207.

Sitzmann, T., \& Johnson, S. K. (2012b). The best laid plans: Examining the conditions under which a planning intervention improves learning and reduces attrition. Journal of Applied Psychology, 97(5), 967.

Sitzmann, T. \& Yeo, G. (2013). A meta-analytic investigation of the within-person self-efficacy domain: Is self-efficacy a product of past performance or a driver of future performance? Personnel Psychology, 66(3), 531-568.

Spangler, W. D. (1992). Validity of questionnaire and TAT measures of need for achievement: Two meta-analyses. Psychological Bulletin, 112(1), 140-154.

Stajkovic, A. D., Locke, E. A., \& Blair, E. S. (2006). A first examination of the relationships between primed subconscious goals, assigned conscious goals, and task performance. Journal of Applied Psychology, 91(5), 1172-1180.

Steel, P. (2007). The nature of procrastination: A meta-analytic and theoretical review of quintessential self-regulatory failure. Psychological Bulletin, 133(1), 65.

Steel, P., \& König, C. J. (2006). Integrating theories of motivation. Academy of Management Review, 31(4), 889-913.

Tasa, K., Celani, A., \& Bell, C. M. (2013). Goals in negotiation revisited: The impact of goal setting and implicit negotiation beliefs. Negotiation and Conflict Management Research, 6(2), 114-132.

Vancouver, J. B. (2000). Self-regulation in industrial/organizational psychology: A tale of two 
paradigms. In M. Boekaerts, P.R. Pintrich, \& M. Zeidner, (Eds.), Handbook of SelfRegulation (pp. 303-341). San Diego, CA: Academic Press.

Vancouver, J. B., \& Kendall, L. N. (2006). When self-efficacy negatively relates to motivation and performance in a learning context. Journal of Applied Psychology, 91(5), 1146-1153.

White, S. S., \& Locke, E. A. (2000). Problems with the Pygmalion effect and some proposed solutions. The Leadership Quarterly, 11(3), 389-415.

Wilson, T. D. (2002). Strangers to ourselves: Discovering the adaptive unconscious. Cambridge, MA: Harvard University Press.

Winters, D., \& Latham, G. P. (1996). The effect of learning versus outcome goals on a simple versus complex task. Group Organization Management, 21, 236-250.

Yeo, G. B., \& Neal, A. (2004). A multilevel analysis of effort, practice, and performance: Effects of ability, conscientiousness, and goal orientation. Journal of Applied Psychology, 89, 231-247.

Zemack-Rugar, Y., Bettman, J. R., \& Fitzsimons, G. J. (2007). The effects of nonconsciously priming emotion concepts on behavior. Journal of Personality and Social Psychology, 93(6), 927-939.

Zhang, Z., Zyphur, M. J., \& Preacher, K. J. (2009). Testing multilevel mediation using hierarchical linear models. Organizational Research Methods, 12, 695-719. 
Table 1

Intraclass Correlation Coefficients, Descriptive Statistics, and Correlations among Study Variables at the Within-and Between-

\section{Person Levels of Analysis}

\begin{tabular}{|c|c|c|c|c|c|c|c|c|c|c|}
\hline Variable & ICC1 & $M$ & $S D$ & 1 & 2 & 3 & 4 & 5 & 6 & 7 \\
\hline 1. Conscious difficult goal (1) vs. neutral goal (0) & - & 0.33 & 0.47 & - & $-.50 *$ & .00 & .00 & -.03 & .02 & .03 \\
\hline 2. Conscious easy goal (1) vs. neutral goal (0) & - & 0.33 & 0.47 & - & - & .00 & .00 & -.01 & -.02 & -.02 \\
\hline 3. Subconscious achievement goal (1) vs. no goal (0) & - & 0.34 & 0.47 & - & - & - & $-.50 *$ & .02 & .01 & -.04 \\
\hline 4. Subconscious underachievement goal (1) vs. no goal (0) & - & 0.33 & 0.47 & - & - & - & - & -.04 & -.05 & .03 \\
\hline 5. Time on task & .53 & 0.49 & 0.43 & - & - & - & - & - & $.09 *$ & - \\
\hline 6. Task performance & .23 & 0.54 & 0.24 & - & - & - & - & $.20 *$ & - & - \\
\hline 7. Goal abandonment & - & 0.88 & 0.33 & - & - & - & - & -.05 & -.10 & - \\
\hline
\end{tabular}

Note. Between-person correlations are below the diagonal and within-person correlations are above the diagonal. Goal abandonment was coded such that 1 indicates that individuals withdrew and 0 indicates that individuals completed the course (for the between-person correlations) or the module (for the withinperson correlations).

$* p<.05$ 
Table 2. The Effects of Goal Setting on Time on Task, Task Performance, and Goal Abandonment

\begin{tabular}{|c|c|c|c|c|c|c|c|}
\hline & $\mathrm{H} 1$ & $\mathrm{H} 2$ & H3 \& H6 & $\mathrm{H} 4$ & H5 & H5 & $\mathrm{H} 7$ \\
\hline & Time on & Task & Task & Goal & Task & Goal & Goal \\
\hline & Task & Performance & Performance & Abandonment & Performance & Abandonment & Abandonment \\
\hline \multirow[t]{2}{*}{ Intercept } & $0.42 \dagger$ & $0.56 \dagger$ & $0.55 \dagger$ & $-0.35 \dagger$ & $0.55 \dagger$ & $-0.80 \dagger$ & $-0.79 \dagger$ \\
\hline & $(0.02)$ & $(0.02)$ & $(0.02)$ & $(0.13)$ & $(0.01)$ & $(0.20)$ & $(0.20)$ \\
\hline \multirow[t]{2}{*}{ Module } & $-0.01 \dagger$ & $-0.01 \dagger$ & 0.00 & $-0.31 \dagger$ & 0.00 & $-0.26 \dagger$ & $-0.26 \dagger$ \\
\hline & $(0.00)$ & $(0.00)$ & $(0.00)$ & $(0.03)$ & $(0.00)$ & $(0.04)$ & $(0.04)$ \\
\hline \multirow[t]{2}{*}{ Conscious difficult goal (1) vs. neutral goal (0) } & -0.01 & 0.01 & 0.00 & 0.19 & 0.01 & 0.27 & 0.23 \\
\hline & $(0.02)$ & $(0.02)$ & $(0.02)$ & $(0.13)$ & $(0.01)$ & $(0.18)$ & $(0.18)$ \\
\hline \multirow[t]{2}{*}{ Conscious easy goal (1) vs. neutral goal (0) } & -0.02 & 0.00 & 0.00 & 0.01 & -0.01 & -0.03 & -0.06 \\
\hline & $(0.02)$ & $(0.02)$ & $(0.02)$ & $(0.14)$ & $(0.01)$ & $(0.19)$ & $(0.19)$ \\
\hline \multirow{2}{*}{$\begin{array}{l}\text { Subconscious achievement goal (1) vs. no } \\
\quad \text { goal (0) }\end{array}$} & $0.03 *$ & 0.03 & 0.02 & 0.12 & -0.01 & 0.04 & 0.04 \\
\hline & $(0.02)$ & $(0.02)$ & $(0.02)$ & $(0.14)$ & $(0.01)$ & $(0.19)$ & $(0.19)$ \\
\hline \multirow{2}{*}{$\begin{array}{l}\text { Subconscious underachievement goal (1) } \\
\quad \text { vs. no goal }(0)\end{array}$} & 0.00 & $-0.05^{*}$ & $-0.06^{*}$ & $0.26^{*}$ & $-0.03^{*}$ & 0.21 & 0.21 \\
\hline & $(0.02)$ & $(0.02)$ & $(0.02)$ & $(0.14)$ & $(0.01)$ & $(0.18)$ & $(0.18)$ \\
\hline \multirow[t]{2}{*}{ Time spent on exam } & & $0.01 \dagger$ & $0.01 \dagger$ & & $0.01 \dagger$ & & \\
\hline & & $(0.00)$ & $(0.00)$ & & $(0.00)$ & & \\
\hline Prior time on task & $\begin{array}{l}0.33 \dagger \\
(0.02)\end{array}$ & & & & & & \\
\hline \multirow[t]{2}{*}{ Prior task performance } & & & & & & $-1.10^{*}$ & 0.25 \\
\hline & & & & & & $(0.33)$ & $(0.58)$ \\
\hline \multirow[t]{2}{*}{ Time on task } & & & $0.07 \dagger$ & & $0.08 \dagger$ & & \\
\hline & & & $(0.02)$ & & $(0.02)$ & & \\
\hline \multirow{2}{*}{$\begin{array}{l}\text { Conscious difficult goal x Subconscious } \\
\text { achievement goal }\end{array}$} & & $-0.05^{*}$ & -0.04 & & & & \\
\hline & & $(0.03)$ & $(0.03)$ & & & & \\
\hline \multirow{2}{*}{$\begin{array}{l}\text { Conscious easy goal x Subconscious } \\
\text { achievement goal }\end{array}$} & & $-0.05 \dagger$ & -0.05 & & & & \\
\hline & & $(0.03)$ & $(0.03)$ & & & & \\
\hline \multirow{2}{*}{$\begin{array}{l}\text { Conscious difficult goal x Subconscious } \\
\text { underachievement goal }\end{array}$} & & 0.05 & $0.07 *$ & & & & \\
\hline & & $(0.03)$ & $(0.03)$ & & & & \\
\hline \multirow{2}{*}{$\begin{array}{l}\text { Conscious easy goal x Subconscious } \\
\text { underachievement goal }\end{array}$} & & 0.02 & 0.03 & & & & \\
\hline & & $(0.03)$ & $(0.03)$ & & & & \\
\hline \multirow[t]{2}{*}{ Conscious difficult goal $\mathrm{x}$ Time on task } & & & $0.06 *$ & & & & \\
\hline & & & $(0.03)$ & & & & \\
\hline \multirow[t]{2}{*}{ Conscious easy goal $\mathrm{x}$ Time on task } & & & 0.01 & & & & \\
\hline & & & $(0.03)$ & & & & \\
\hline \multirow{2}{*}{$\begin{array}{l}\text { Conscious difficult goal x Prior task } \\
\text { performance }\end{array}$} & & & & & & & $-2.17 *$ \\
\hline & & & & & & & $(0.80)$ \\
\hline \multirow{2}{*}{$\begin{array}{l}\text { Conscious easy goal x Prior task } \\
\text { performance }\end{array}$} & & & & & & & $-1.75 \dagger$ \\
\hline & & & & & & & $(0.80)$ \\
\hline
\end{tabular}


Subconscious Goal Pursuit 51

Note: $\mathrm{H}$ indicates hypothesis. $\dagger p<.05$ (two-tailed for non-hypothesized effects). ${ }^{*} p<.05$ (one-tailed for hypothesized effects)

$N=1,294$ for the analysis predicting time on task, 1,450 for the analyses predicting task performance, 6,160 for the non-time lagged analysis predicting goal abandonment, and 1,310 for the time lagged analysis predicting goal abandonment. 
Figure 1. Conceptual model of the effects of subconscious achievement and underachievement goals.

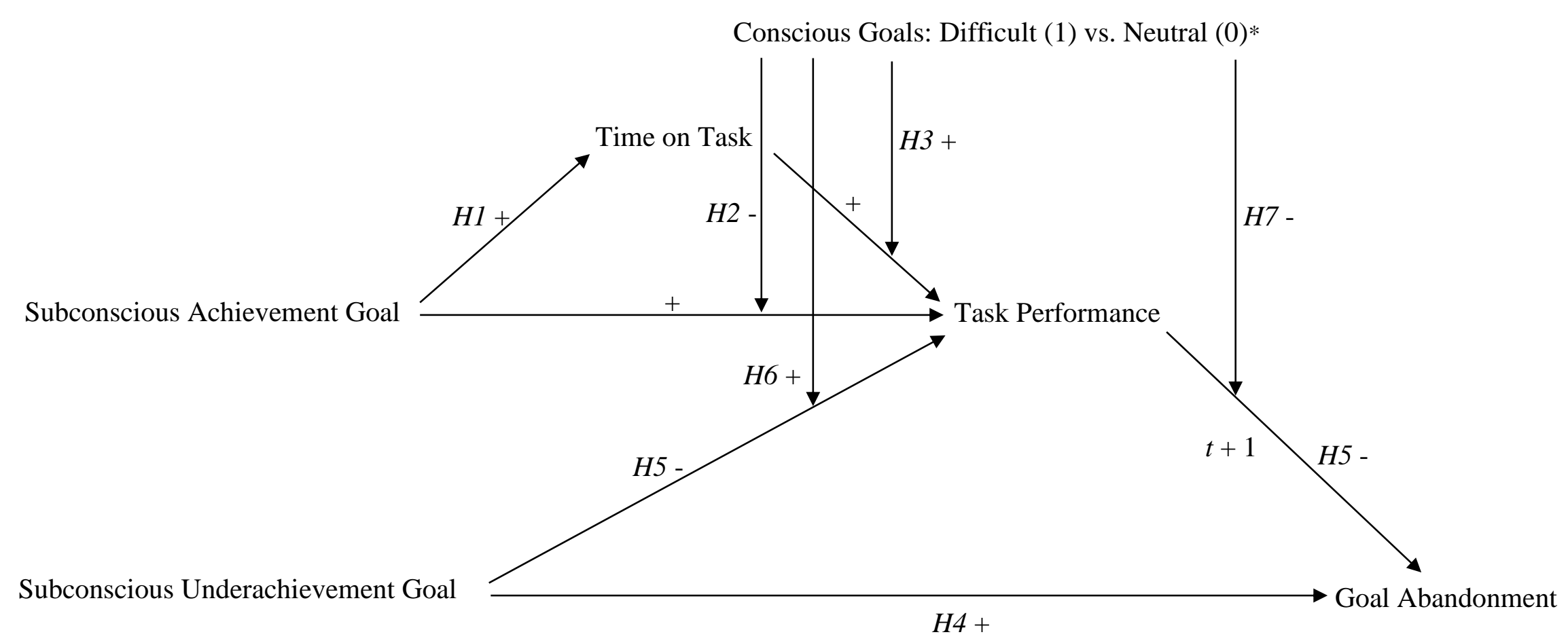

Note: $t+1$ denotes a time-lagged effect

*Along with the difficult and neutral conscious goal conditions, we included an easy conscious goal condition but do not hypothesize that easy goals will differ from neutral goals on the effects under investigation. 
Figure 2. Interaction between subconscious and conscious goals when predicting task performance.

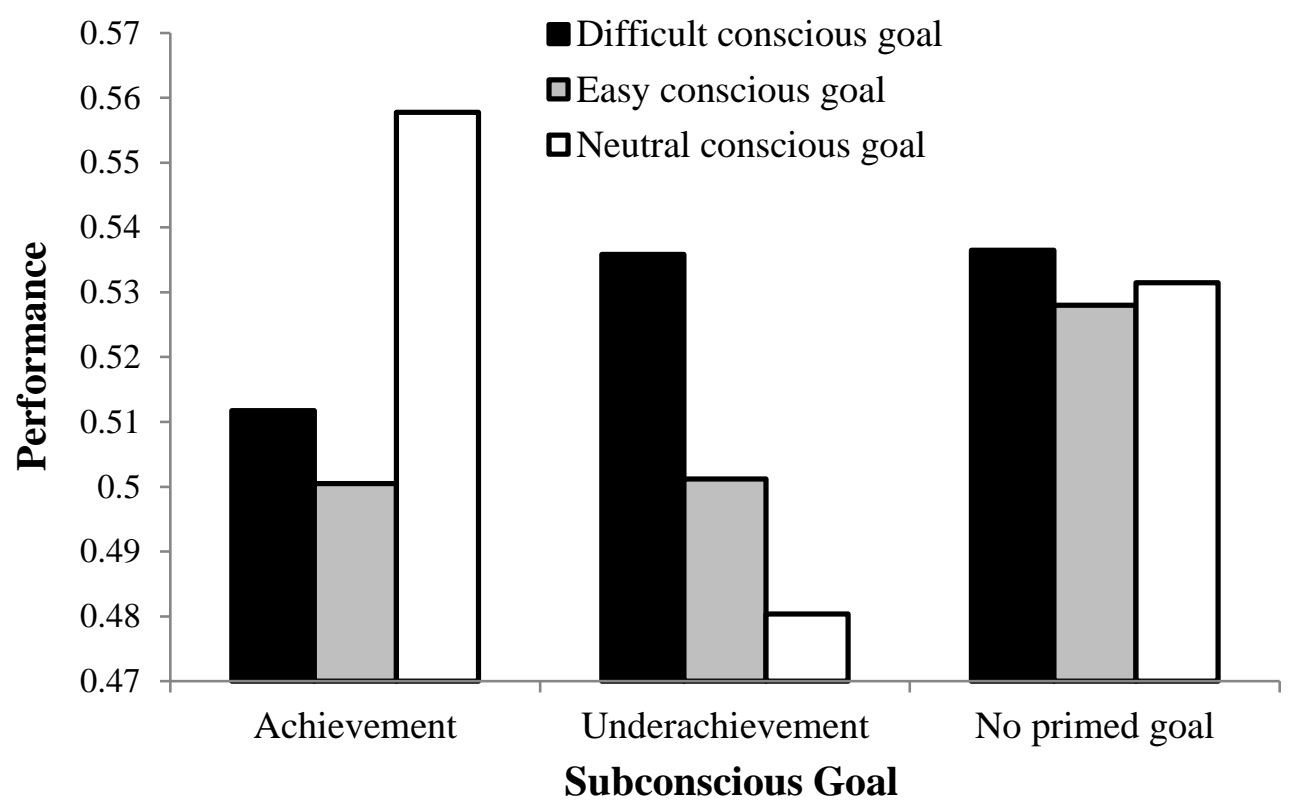


Figure 3. Interaction between time on task and conscious goals when predicting task performance.

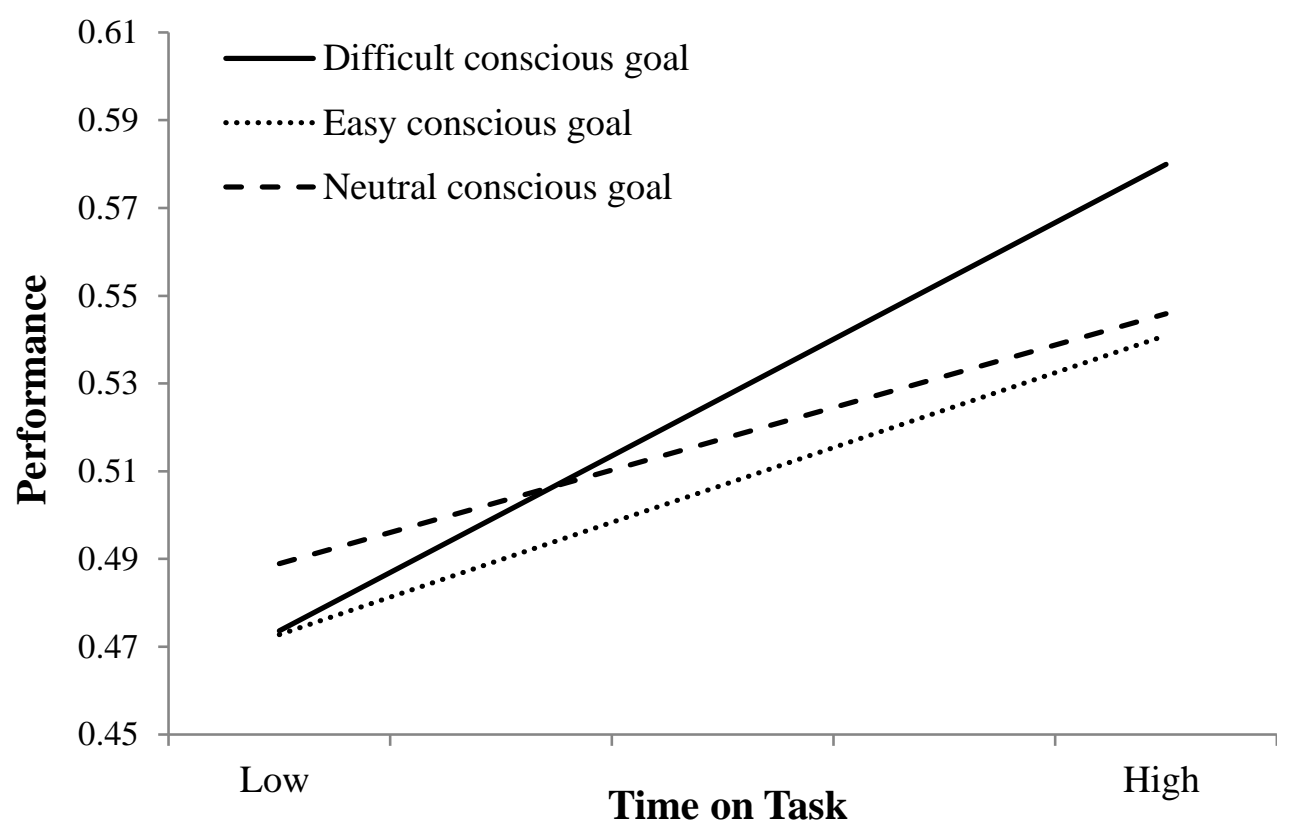


Figure 4. Interaction between prior task performance and conscious goals when predicting goal abandonment.

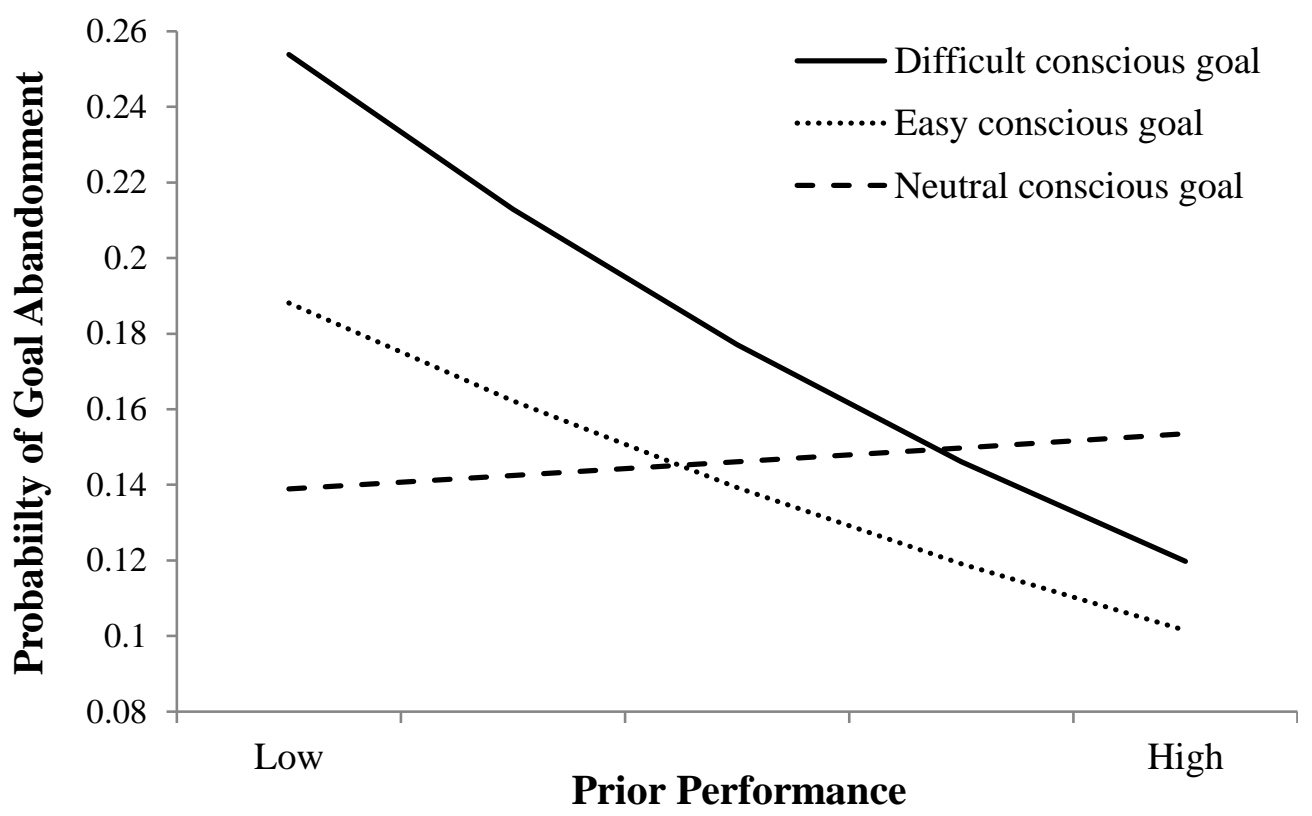




\section{Appendix}

Pattern of Conscious and Subconscious Goals and Sample Sizes across Experimental Conditions and Training Modules

\begin{tabular}{|c|c|c|c|c|c|c|c|c|c|c|c|c|c|c|c|c|c|c|}
\hline \multirow[b]{2}{*}{ Module } & \multicolumn{2}{|c|}{$\begin{array}{c}\text { Condition } \\
1 \\
\end{array}$} & \multicolumn{2}{|c|}{$\begin{array}{c}\text { Condition } \\
2 \\
\end{array}$} & \multicolumn{2}{|c|}{$\begin{array}{c}\text { Condition } \\
3 \\
\end{array}$} & \multicolumn{2}{|c|}{$\begin{array}{c}\text { Condition } \\
4 \\
\end{array}$} & \multicolumn{2}{|c|}{$\begin{array}{c}\text { Condition } \\
5 \\
\end{array}$} & \multicolumn{2}{|c|}{$\begin{array}{c}\text { Condition } \\
6\end{array}$} & \multicolumn{2}{|c|}{$\begin{array}{c}\text { Condition } \\
7 \\
\end{array}$} & \multicolumn{2}{|c|}{$\begin{array}{c}\text { Condition } \\
8 \\
\end{array}$} & \multicolumn{2}{|c|}{$\begin{array}{c}\text { Condition } \\
9\end{array}$} \\
\hline & Goals & $N$ & Goals & $N$ & Goals & $N$ & Goals & $N$ & Goals & $N$ & Goals & $N$ & Goals & $N$ & Goals & $N$ & Goals & $N$ \\
\hline \multirow[t]{2}{*}{1} & DCG & 31 & DCG & 43 & DCG & 33 & $\mathrm{NCG}$ & 36 & $\mathrm{NCG}$ & 39 & $\mathrm{NCG}$ & 30 & ECG & 29 & $\mathrm{ECG}$ & 41 & $\mathrm{ECG}$ & 27 \\
\hline & ASG & 37 & NSG & 36 & USG & 37 & $\mathrm{ASG}$ & 31 & NSG & 35 & USG & 34 & ASG & 33 & $\mathrm{NSG}$ & 31 & USG & 33 \\
\hline \multirow[t]{2}{*}{2} & $\mathrm{NCG}$ & 21 & $\mathrm{NCG}$ & 35 & ECG & 21 & DCG & 22 & DCG & 24 & ECG & 20 & ECG & 25 & $\mathrm{NCG}$ & 26 & DCG & 14 \\
\hline & $\mathrm{ASG}$ & 10 & NSG & 8 & $\mathrm{ASG}$ & 12 & $\mathrm{NSG}$ & 14 & USG & 15 & USG & 10 & $\mathrm{NSG}$ & 4 & USG & 15 & ASG & 13 \\
\hline \multirow[t]{2}{*}{3} & $\mathrm{NCG}$ & 16 & ECG & 28 & $\mathrm{NCG}$ & 16 & $\mathrm{DCG}$ & 21 & ECG & 19 & $\mathrm{DCG}$ & 18 & $\mathrm{DCG}$ & 22 & ECG & 23 & $\mathrm{NCG}$ & 11 \\
\hline & USG & 5 & NSG & 7 & $\mathrm{ASG}$ & 5 & $\mathrm{ASG}$ & 1 & $\mathrm{ASG}$ & 5 & NSG & 2 & USG & 3 & USG & 3 & NSG & 3 \\
\hline \multirow[t]{2}{*}{4} & $\mathrm{DCG}$ & 11 & $\mathrm{NCG}$ & 23 & $\mathrm{ECG}$ & 13 & $\mathrm{ECG}$ & 20 & $\mathrm{NCG}$ & 16 & ECG & 14 & $\mathrm{NCG}$ & 16 & $\mathrm{DCG}$ & 18 & $\mathrm{DCG}$ & 9 \\
\hline & $\mathrm{NSG}$ & 5 & $\mathrm{ASG}$ & 5 & USG & 3 & ASG & 1 & USG & 3 & $\mathrm{NSG}$ & 4 & $\mathrm{NSG}$ & 6 & $\mathrm{ASG}$ & 5 & USG & 2 \\
\hline \multirow[t]{2}{*}{5} & ECG & 9 & DCG & 20 & $\mathrm{ECG}$ & 12 & $\mathrm{NCG}$ & 17 & $\mathrm{ECG}$ & 10 & $\mathrm{NCG}$ & 14 & $\mathrm{DCG}$ & 14 & $\mathrm{DCG}$ & 13 & $\mathrm{NCG}$ & 6 \\
\hline & $\mathrm{ASG}$ & 2 & $\mathrm{ASG}$ & 3 & $\mathrm{NSG}$ & 1 & NSG & 3 & USG & 6 & $\mathrm{ASG}$ & 0 & NSG & 2 & USG & 5 & USG & 3 \\
\hline \multirow[t]{2}{*}{6} & ECG & 7 & ECG & 20 & $\mathrm{NCG}$ & 12 & $\mathrm{NCG}$ & 17 & $\mathrm{ECG}$ & 9 & $\mathrm{DCG}$ & 12 & $\mathrm{DCG}$ & 13 & $\mathrm{DCG}$ & 11 & $\mathrm{NCG}$ & 3 \\
\hline & USG & 2 & ASG & 0 & NSG & 0 & USG & 0 & NSG & 1 & USG & 2 & ASG & 1 & NSG & 2 & ASG & 3 \\
\hline \multirow[t]{2}{*}{7} & $\mathrm{ECG}$ & 6 & $\mathrm{NCG}$ & 19 & $\mathrm{DCG}$ & 11 & $\mathrm{DCG}$ & 14 & $\mathrm{DCG}$ & 8 & $\mathrm{NCG}$ & 10 & ECG & 12 & $\mathrm{NCG}$ & 10 & ECG & 3 \\
\hline & $\mathrm{NSG}$ & 1 & USG & 1 & $\mathrm{NSG}$ & 1 & USG & 3 & $\mathrm{ASG}$ & 1 & $\mathrm{NSG}$ & 2 & USG & 1 & $\mathrm{ASG}$ & 1 & ASG & 0 \\
\hline \multirow[t]{2}{*}{8} & $\mathrm{NCG}$ & 6 & $\mathrm{DCG}$ & 17 & $\mathrm{NCG}$ & 10 & ECG & 13 & $\mathrm{DCG}$ & 6 & $\mathrm{DCG}$ & 10 & $\mathrm{NCG}$ & 12 & ECG & 10 & ECG & 3 \\
\hline & NSG & 0 & USG & 2 & USG & 1 & USG & 1 & NSG & 2 & ASG & 0 & ASG & 0 & ASG & 0 & NSG & 0 \\
\hline \multirow[t]{2}{*}{9} & $\mathrm{DCG}$ & 4 & ECG & 16 & $\mathrm{DCG}$ & 9 & ECG & 12 & $\mathrm{NCG}$ & 6 & ECG & 9 & $\mathrm{NCG}$ & 12 & $\mathrm{NCG}$ & 9 & $\mathrm{DCG}$ & 3 \\
\hline & USG & 2 & USG & 1 & $\mathrm{ASG}$ & 1 & NSG & 1 & $\mathrm{ASG}$ & 0 & ASG & 1 & USG & 0 & $\mathrm{NSG}$ & 1 & NSG & 0 \\
\hline \multirow[t]{2}{*}{10} & ECG & 4 & $\mathrm{NCG}$ & 16 & $\mathrm{DCG}$ & 8 & $\mathrm{DCG}$ & 10 & $\mathrm{NCG}$ & 6 & ECG & 8 & $\mathrm{DCG}$ & 12 & $\mathrm{NCG}$ & 9 & ECG & 3 \\
\hline & $\mathrm{ASG}$ & 0 & $\mathrm{ASG}$ & 0 & USG & 1 & $\mathrm{ASG}$ & 2 & NSG & 0 & NSG & 1 & NSG & 0 & USG & 0 & USG & 0 \\
\hline
\end{tabular}

Note: DCG = Difficult conscious goal; ECG = Easy conscious goal; NCG = Neutral conscious goal; ASG = Achievement subconscious goal; USG =

Underachievement subconscious goal; $\mathrm{NSG}=$ Neutral subconscious goal. $N=$ Number of participants who completed the module (top number) and the number who dropped out in the module (bottom number). 